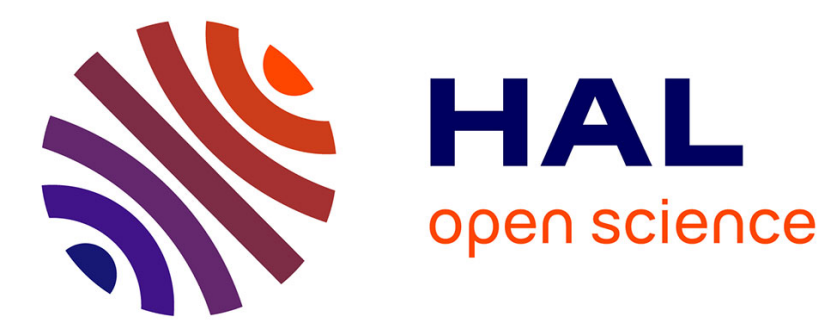

\title{
Materials for Transparent Electrodes: From Metal Oxides to Organic Alternatives
}

\author{
Anna Isabel Hofmann, Eric Cloutet, Georges Hadziioannou
}

\section{To cite this version:}

Anna Isabel Hofmann, Eric Cloutet, Georges Hadziioannou. Materials for Transparent Electrodes: From Metal Oxides to Organic Alternatives. Advanced Electronic Materials, 2018, 10.1002/aelm.201700412 . hal-01688624

\section{HAL Id: hal-01688624 \\ https://hal.science/hal-01688624}

Submitted on 28 Aug 2020

HAL is a multi-disciplinary open access archive for the deposit and dissemination of scientific research documents, whether they are published or not. The documents may come from teaching and research institutions in France or abroad, or from public or private research centers.
L'archive ouverte pluridisciplinaire HAL, est destinée au dépôt et à la diffusion de documents scientifiques de niveau recherche, publiés ou non, émanant des établissements d'enseignement et de recherche français ou étrangers, des laboratoires publics ou privés. 
Article type: Review

Materials for Transparent Electrodes: From Metal Oxides to Organic Alternatives

Anna I. Hofmann, Eric Cloutet*, Georges Hadziioannou*

Dr. A. I. Hofmann, Dr. E. Cloutet, Prof. G. Hadziioannou

Université Bordeaux/CNRS/INP, Laboratoire de Chimie des Polymères Organiques, Allée

Geoffroy Saint Hilaire, Bâtiment B8, 33615 Pessac Cedex, France

E-mail : cloutet@enscbp.fr

Dr. A. I. Hofmann

Chalmers University of Technology, Department of Chemistry and Chemical Engineering, 41296 Göteborg, Sweden

Keywords: Transparent Conductors, Composite Materials, Conducting Polymers, Nanostructures, Flexible Electronics

Abstract

Nowadays, opto-electronic devices, such as displays, are omnipresent in our daily life. A crucial component of these devices is a transparent electrode, which allows the in- and out-coupling of light. With the goal of optimizing the electrode characteristics and improving device efficiencies, many approaches for the fabrication of thin, transparent conducting films have been studied. This review gives an overview of the different material classes which have been 
used as transparent electrodes, ranging from metal oxides, such as Indium Tin Oxide, metal and carbonaceous nanostructures, to conducting polymers and composites. For every material class a brief description of the fundamental principles, processing routes and the latest achievements is given. Furthermore, the different electrodes are compared regarding their opto-electronic performance, flexibility and surface roughness. Ultimately, advantages and drawbacks of the respective electrodes are discussed. This critical comparison of fundamentally different transparent conducting materials allows, on one hand, to make a sensible choice of electrode for specific applications, and, on the other hand, to point out scientific challenges that must still be addressed.

\section{Introduction}

Nowadays electronic devices are omnipresent in our everyday life and have improved the standard of living in so many fields, such as communication, entertainment, health and security, that our modern society can not be imagined without electronics. A new class of electronics which has recently attracted a lot of attention are organic electronics, which pave the way for the development of cost-efficient, flexible, light-weight and bio-compatible electronic devices. Prominent examples for opto-electronic, organic devices are organic light emitting diodes (OLEDs) and organic photovoltaics (OPVs). OLEDs and OPVs are sandwich structures, which are composed of several layers.. Each of these layers serves a specific purpose and the judicious choice of the different materials, layer thicknesses and processing methods allows the optimization of the device performanceIndependently of the exact device structure, a common crucial component in all OLED and OPV devices is a transparent electrode, which allows the in- or out-coupling of light.

The crucial characteristics of transparent electrodes are a low sheet resistance $R_{s}$ in combination with a high transmittance $T$ in the UV/Vis to near IR region. To simplify the comparison of different materials, it is common use to measure the transmittance $T$ at $550 \mathrm{~nm}$, even if a single 
transmittance value is not necessarily representative for the whole UV/Vis-NIR absorption spectrum. By plotting $T$ as a function of $R_{s}$ the opto-electronic properties of different materials and of films with different thicknesses can be compared (see Figure 1). Materials with the "best" opto-electronic performance can be found in the top left of the graph, as indicated by the green box. For thin conducting films the sheet resistance $R_{s}$ and the transmittance $T$ can be related via ${ }^{[1]}$

$$
T=\left(1+\frac{188.5 \sigma_{o p t}}{R_{S} \sigma_{D C}}\right)^{-2}
$$

with $\sigma_{o p t}$ being the optical conductivity and $\sigma_{D C}$ being the direct current (DC) conductivity. The DC conductivity $\sigma_{D C}$ is frequency independent and relates the current density $\vec{\jmath}$ with the applied static electrical field $\vec{E}(\omega=0)$ via the Ohm's law

$$
\vec{\jmath}=\sigma_{D C} \vec{E}
$$

The optical conductivity $\sigma_{o p t}$ is the frequency dependent conductivity $\sigma(\omega)$ under the influence of an external alternating electromagnetic field $\vec{E}(\omega \neq 0)$, with $\omega$ in the optical frequency range. Using the Lambert-Beer's law $\sigma(\omega)$ can be related to the film transmission.

In order to facilitate the comparison of the opto-electronic properties of transparent conducting films the ratio $\sigma_{D C} / \sigma_{o p t}$ can be used as figure of merit (FoM). Via transformation of Equation 1 we obtain

$$
F o M=\frac{\sigma_{D C}}{\sigma_{o p t}}=\frac{188.5}{\left(\frac{1}{\sqrt{T}}-1\right) R_{S}}
$$


which shows that the FoM is maximized for high transmittance at low sheet resistance. The solid lines in Figure 1a represent the calculated $R_{s}-T$ values for a constant FoM.

However, it has to be taken into account, that the Equation (1) was established for free standing films ${ }^{[1]}$, whereas in experimental practice most thin transparent films are measured on glass or plastic substrates. Furthermore, the FoM diverges per definition for very high transmittance values $>95 \%$ and extremely low sheet resistance values. This is illustrated in Figure $1 \mathrm{~b}$, which displays the dependencies of the FoM on $R_{S}\left(\mathrm{FoM} \propto R_{S}{ }^{-1}\right.$, pink curve $)$ and on $T\left(\mathrm{FoM} \propto\left(\mathrm{T}^{-0.5}-\right.\right.$ $1)^{-1}$, black curve).

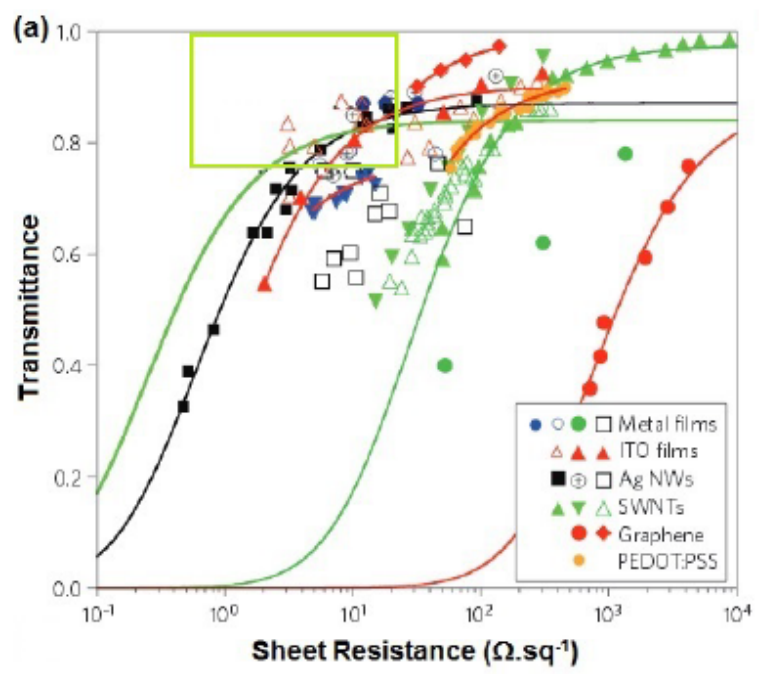

' (b)
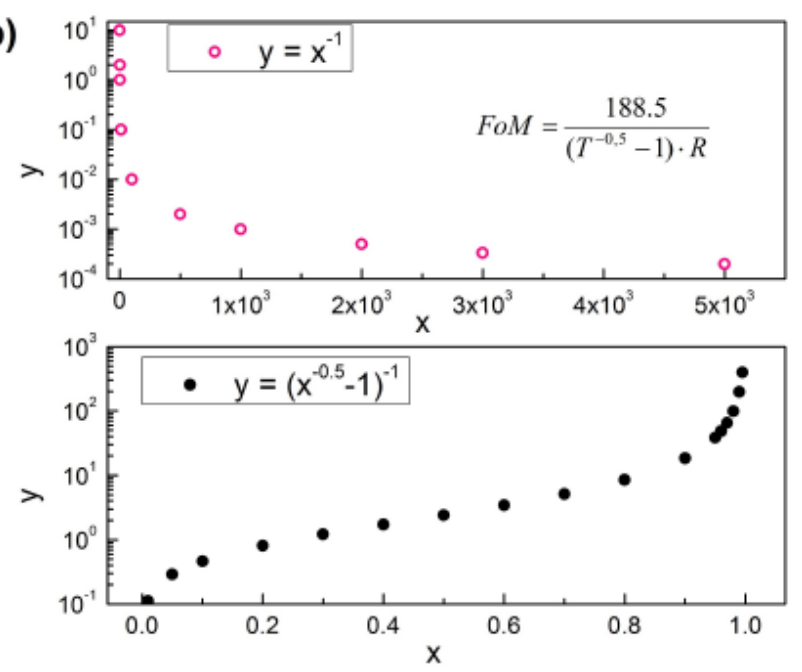

Figure 1 a) Transmittance versus sheet resistance for transparent conducting films made of different materials $^{[1]}$ (Reproduced with permission 2012, Nature Publishing Group) and b) plot illustrating the qualitative dependencies of the FoM on the trasmittance $\mathrm{T}$ and on the sheet resistance $\mathrm{R}_{\mathrm{s}}$.

Two other thickness independent measures, which are commonly used to characterize transparent electrodes are the conductivity $\sigma$ and the absorption coefficient $a$, which can be calculated using 


$$
\sigma=\frac{1}{R_{S} d}
$$

$$
a=\frac{A}{d}=\frac{-\log _{10}(T)}{d}
$$

with $R_{S}$ being the sheet resistance, $T$ the transmittance, $d$ the film thickness and $A$ the absorbance.

The conductivity $\sigma$ of a material depends on the charge carrier density $N$ and on the charge carrier mobility $\mu$ and can be expressed as

$$
\sigma=N \mu q
$$

with $q$ being the elementary charge. Therefore, both the charge carrier density and the charge carrier mobility must be maximized in order to obtain a highly conducting material. While the charge carrier density of a semiconductor can be enhanced by the so-called doping, the charge carrier mobility is strongly dependent on the micro and nano structure of the film.

Generally speaking, the device performance will be improved for a transparent electrode with maximum conductivity at minimum absorption.

In order to be considered for industrial application, a transparent electrode material should show a sheet resistance of less than $100 \mathrm{Ohm} \mathrm{sq}^{-1}$ at more than $90 \%$ transmittance, which corresponds to a FoM of higher than $34 .{ }^{[2]}$ However, the exact requirements on the electrode performance depend strongly on each specific application. ${ }^{[3,4]}$ For the fabrication of OLEDs, for instance, the decisive criterion is a high conductivity ${ }^{[3]}$, whereas the integration in OPV devices necessitates a very high transparency. ${ }^{[4]}$ 
Besides good opto-electronic properties, another crucial criterion for the integration in devices is the work function of the electrode material, which should be close to the HOMO level of the active layer material, in order to ensure efficient hole extraction (OPV) or injection (OLED), as exemplary illustrated in Figure 2. Further criteria are a smooth electrode surface, to avoid short circuits and high leakage currents, good chemical stability for long device lifetimes, easy and cost efficient processing as well as flexibility, for the application in flexible devices.

There are different classes of materials which can be used to fabricate thin, transparent and conducting films that can serve as transparent electrode in opto-electronic devices. In this review we give an overview of inorganic and organic materials which have been studied as transparent electrode materials. Besides their opto-electronic properties also their mechanical stability, surface roughness and chemical stability will be discussed and a brief overview of the main processing routes will be given. This allows a direct comparison of the different types of transparent electrodes, which have been studied in literature, and helps to point out their respective advantages and drawbacks for diffent applications.
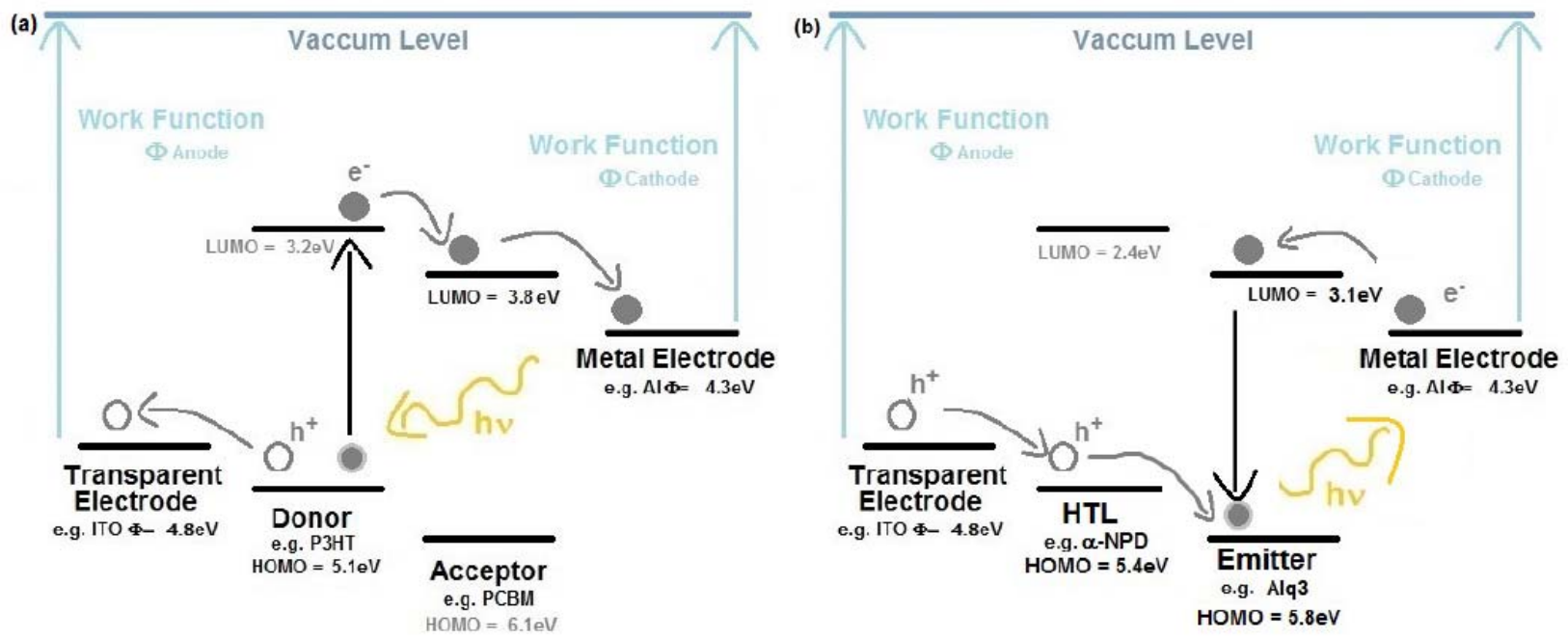

Figure 2 Schematic diagram of the energy levels in an a) OPV device in case of a bulk hetero junction with a P3HT:PCBM active layer and an ITO transparent anode and an Al cathode and 
b) OLED device with an $\alpha$-NPD hole transport layer (HTL) and an Alqa emitting layer and an ITO transparent anode and an Al cathode

1. Inorganic Transparent Conducting Films

\subsection{Metal Oxides}

\subsubsection{Indium Tin Oxide (ITO)}

Due to its outstanding opto-electronic properties the current bench mark material for transparent electrodes is the inorganic metal oxide Indium Tin Oxide (ITO). It is formed by doping of indium oxide $\operatorname{In}_{2} \mathrm{O}_{3}$ with tin ( $\mathrm{Sn}$ ) impurities, which substitute indium cations in the $\mathrm{In}_{2} \mathrm{O}_{3}$ cubic bixbyite lattice. The $\operatorname{In}_{2} \mathrm{O}_{3}$ cubic bixbyite lattice can be described as a face-centered-cubic (fcc) $\mathrm{In}^{3+}$ lattice, in which $\mathrm{O}^{-2}$ anions occupy three fourths of the tetrahedral sites of. Upon oxidation of the tin impurities, electrons are released to the conduction band of ITO, which results in an increase of the charge carrier density in the conduction band of the material and leads to an enhancement of its conductivity. Therefore, Sn can be regarded as a n-type donor for indium oxide. A detailed discussion of the electronic structure, optical properties and conduction mechanism can be found in reference [5]. ${ }^{[5]}$

As already mentioned, ITO displays a very high electric conductivity in the range of $10^{4} \mathrm{~S} \mathrm{~cm}^{-}$

${ }^{1}$ and a high charge carrier concentration of approximately $10^{21} \mathrm{~cm}^{-3} \cdot{ }^{[6,7]}$ Furthermore, it shows a very high transmittance of more than $80 \%$ in the visible range $(370 \mathrm{~nm}<\lambda<1000 \mathrm{~nm})^{[6,7]}$, which is related to its wide band gap of more than $3.75 \mathrm{eV}$. Together with its high conductivity, this results in a FoM of up to 500. The work function of ITO was reported to be between 4.3 $\mathrm{eV}$ and $4.8 \mathrm{eV}$, depending on the fabrication method and on the surface post-treatment of the film. ${ }^{[8-11]}$ Several studies have shown, that mechanical cleaning of the ITO surface with paper 
or Teflon, as well as wet chemical cleaning in common organic solvents resulted in a decrease of the measured work function, whereas a treatment with aqua regina, UV/Ozone or oxygen plasma lead to an increase of the work function. ${ }^{[8,9,11]}$ This can be partially explained by the influence of organic contaminations and the surface composition on the work function. The predominant influence factor, however, was found to be the oxygen concentration on the ITO surface. ${ }^{[9]}$ Using simple surface treatments on ITO electrodes is of big interest for the device fabrication, as it allows to increase the work function for better hole injection, while the high bulk conductivity is retained. ${ }^{[12]}$ In this way the device efficiency can be drastically increased. $^{[13]}$

The production of thin ITO films with controlled thickness and doping can be realized by different methods like sputtering, thermal or electron beam evaporation, pulsed laser deposition, chemical vapor deposition (CVD) or sol-gel processes. A more detailed overview and description of the main fabrication techniques of ITO and other metal oxides was given by Chopra et al. ${ }^{[14]}$, Bel Hadj Tahar et al. ${ }^{[15]}$ and Yu et al. ${ }^{[16]}$

The most studied processing routes of ITO are based on evaporation and sputtering methods. Particularly magnetron sputtering is widely used as it allows the deposition of ITO at high rates on large areas at relatively low substrate temperatures. ${ }^{[15]}$ It has been demonstrated that the chosen fabrication method and the exact processing parameters, such as the geometry of the setup, the temperature of the substrate, the gas pressure, the film thickness and annealing steps, have a decisive influence on the structure and the opto-electronic properties of the obtained ITO films (see Figure 3). ${ }^{[15,17-22]}$ In the case of sputtered ITO for instance, the sputtering power has a major influence on the charge carrier concentration and charge carrier mobility, the preferential grain orientation, as well as on the optical film properties. ${ }^{[18-20]}$ Also the oxygen pressure was shown to affect the charge carrier density and mobility ${ }^{[22]}$, as well as the grain size. ${ }^{[18]}$ The surface roughness of sputtered ITO films $\left(R_{s} \approx 10 \mathrm{Ohm} \mathrm{sq}^{-1}, 85 \%\right.$ transmittance, FoM=223) on glass is in the range of several nanometers to tenths of nanometers, depending 
on the fabrications conditions. ${ }^{[17,23]}$ In case of ITO films made by pulsed laser deposition it was found that an increase in the substrate temperature resulted in a higher charge carrier density, whereas an increasing film thickness resulted in an increased grain size, both leading to an improvement of the conductivity. ${ }^{[17]}$ An increase of the partial oxygen pressure was reported to result in the formation of bigger grains, which is supposed to be beneficial for the charge transport due to less scattering at grain boundaries. However, at high oxygen pressure the number of oxygen vacancies in the ITO film is reduced, leading to a reduction of the charge carrier density. Therefore an optimal partial oxygen pressure has to be determined for the chosen evaporation process. Upon optimization of the pulsed laser deposition process, using a partial oxygen pressure of 10 torr and a substrate temperature of $300{ }^{\circ} \mathrm{C}$, Kim et al..$^{[17]}$ obtained $170 \mathrm{~nm}$ thick ITO films composed of $5 \mathrm{wt} \% \mathrm{SnO}_{2}$ and $95 \mathrm{wt} \% \mathrm{In}_{2} \mathrm{O}_{3}$ with a conductivity of $5000 \mathrm{~S} \mathrm{~cm}^{-1}$ at $92 \%$ transmittance and a surface roughness of only $4 \mathrm{~nm}$.
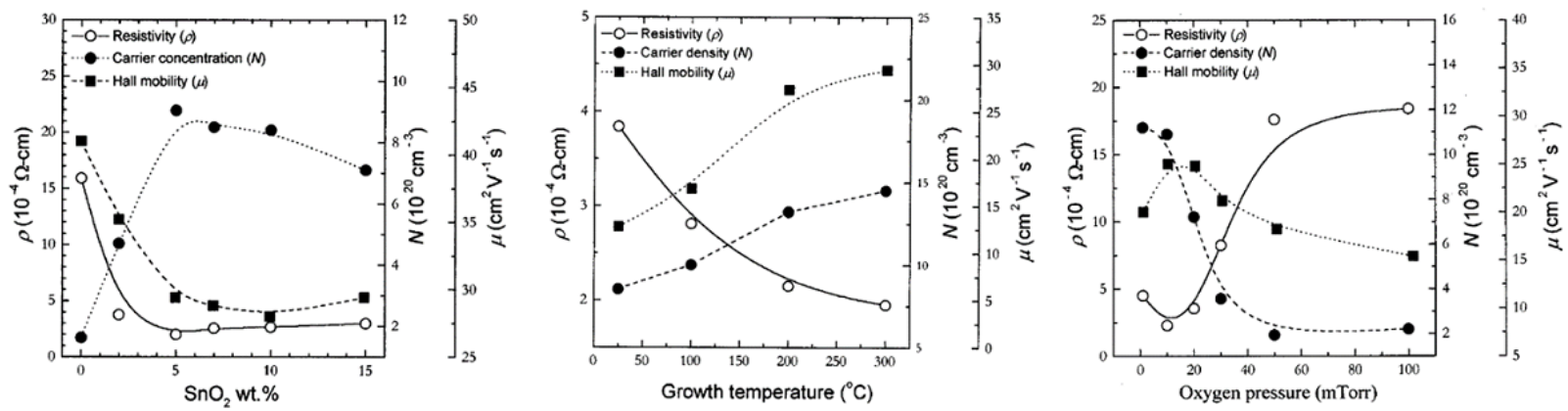

Figure 3 Evolution of resistivity, carrier concentration and carrier mobility (Hall mobility) in ITO fabricated by pulsed laser deposition as a function of tin concentration, growth temperature and oxygen pressure. ${ }^{[17]}$ (Reproduced with permission. 1997, AIP Publishing LLC)

Due to the increasing demand for flexible transparent electrodes, thin ITO films have been deposited on polyethylene terephthalate (PET) substrates. $200 \mathrm{~nm}$ thick ITO films on PET, deposited by pulsed laser deposition at $25{ }^{\circ} \mathrm{C}$ under 45 mtorr oxygen pressure, displayed a 
conductivity of about $1400 \mathrm{~S} \mathrm{~cm}^{-1}$ at $87 \%$ transmittance and were integrated in LED devices, which showed comparable performance as the ITO/glass reference devices $\left(1.6 \mathrm{~lm} \mathrm{~W}^{-1}\right.$ and 100 $\left.\mathrm{cd} \mathrm{m}^{-2}\right) \cdot{ }^{[21]}$ Commercially available ITO/PET films are fabricated by sputtering and reach conductivities of maximum $1700 \mathrm{~S} \mathrm{~cm}^{-1}\left(R_{s} 60\right.$ to $\left.400 \mathrm{Ohm} \mathrm{sq}^{-1}\right)$ at $80 \%$ transmittance (FoM: 4 to 26), the limiting factor for the conductivity being the low substrate temperature and the high deposition rates. ${ }^{[24]}$

Considering the big number of different parameters and the complexity of the ITO system, the processing parameters must be optimized for each specific deposition process. Nevertheless, upon optimization of the individual processing routes ITO films with very similar optoelectronic properties can be obtained. Typically ITO films, deposited on glass by evaporation or sputtering, contain $5 \mathrm{wt} \%$ to $10 \mathrm{wt} \%$ tin, and their conductivities are in the range of 10 to $10^{4}$ $\mathrm{S} \mathrm{cm}^{-1}$ with the transmittance attaining more than $85 \%$ in the visible range. ${ }^{[15]}$

As these above discussed fabrication routes are cost intensive, efforts have been made to fabricate thin ITO films using wet chemical processes, such as sol-gel processes ${ }^{[25-29]}$, solutions of dispersed nanoparticles ${ }^{[28,30]}$ or spray pyrolysis ${ }^{[31-33]}$. The big advantage of the fabrication of ITO films from solutions of dispersed nanocrystals is the simplicity of a one-pot coating process. However, the obtained conductivities are rather low (approximately $330 \mathrm{~S} \mathrm{~cm}^{-1}, R_{S}=$ $100 \mathrm{Ohm} \mathrm{sq}^{-1}$ at $88 \%$ transmittance, FoM=29), which could be related by a high contact resistance between the single nano-particles. ${ }^{[28,30]}$ For the fabrication of ITO via spray pyrolysis a solution of Indium and tin salts (e.g. indium (III) acetate and $\mathrm{SnCl}_{2}$ ) is sprayed onto a heated substrate, on which a thin ITO film is formed.$^{[31-33]}$ Only recently Fellahi et al. ${ }^{[33]}$ reported promising opto-electronic properties for such ITO films (5 wt $\% \mathrm{Sn}, 310^{3} \mathrm{~S} \mathrm{~cm}^{-1}$ at $94 \%$ transmittance). In a typical sol-gel process an aqueous or organic precursor solution, containing an indium salt and an organic stabilizing agent, is spun or spray coated into a thin film, which is subsequently annealed in order to densify the film and remove volatile organic components (see Figure 4). ${ }^{[25-27,29]}$ Already in 1991 Mattox $^{[25]}$ reported the fabrication of thin ITO films (8 
at $\%$ of $\mathrm{Sn}$ ) by sol-gel processing, which, after annealing at $500{ }^{\circ} \mathrm{C}$ in air, displayed a conductivity of approximately $100 \mathrm{~S} \mathrm{~cm}^{-1}$ and a transmittance higher than $85 \%$. More recently Alam et al. ${ }^{[27]}$ reported the fabrication of $250 \mathrm{~nm}$ thick sol-gel processed ITO films with conductivities of up to $1250 \mathrm{~S} \mathrm{~cm}^{-1}$ and $89 \%$ transmittance A direct comparison of the optoelectronic properties of sputtered and sol-gel processed ITO was made by Duta et al. ${ }^{[29]}$, demonstrating that, upon optimization, sol-gel processed ITO film can display comparable performance as sputtered ITO films. The main common advantage of the discussed wet chemical processes for the fabrication of ITO is that they allow the relatively cost efficient production of ITO films on large areas by the means of simple equipment.

All the examples given in this section so far concerned Sn doped indium oxide, as it is currently the benchmark materials for inorganic transparent electrodes. However, it has been shown that indium oxide can also be efficiently doped by other elements such as $\mathrm{Si}$, Ga or $\mathrm{Mo}^{[34-37]}$. Gallium doped $\mathrm{In}_{2} \mathrm{O}_{3}$ for instance, was reported to display conductivities in the range of $10^{3}$ to $10^{4} \mathrm{Scm}^{-1}$ and extremely high electron mobilities of $50 \mathrm{~cm}^{2} \mathrm{~V}^{-1} \mathrm{~s}^{-1[34,36,37]}$, whereas doping of $\mathrm{In}_{2} \mathrm{O}_{3}$ with molybdenum resulted in improved transmittance in the visible regime as compared to tin doped $\mathrm{InO}^{[35]}$. 

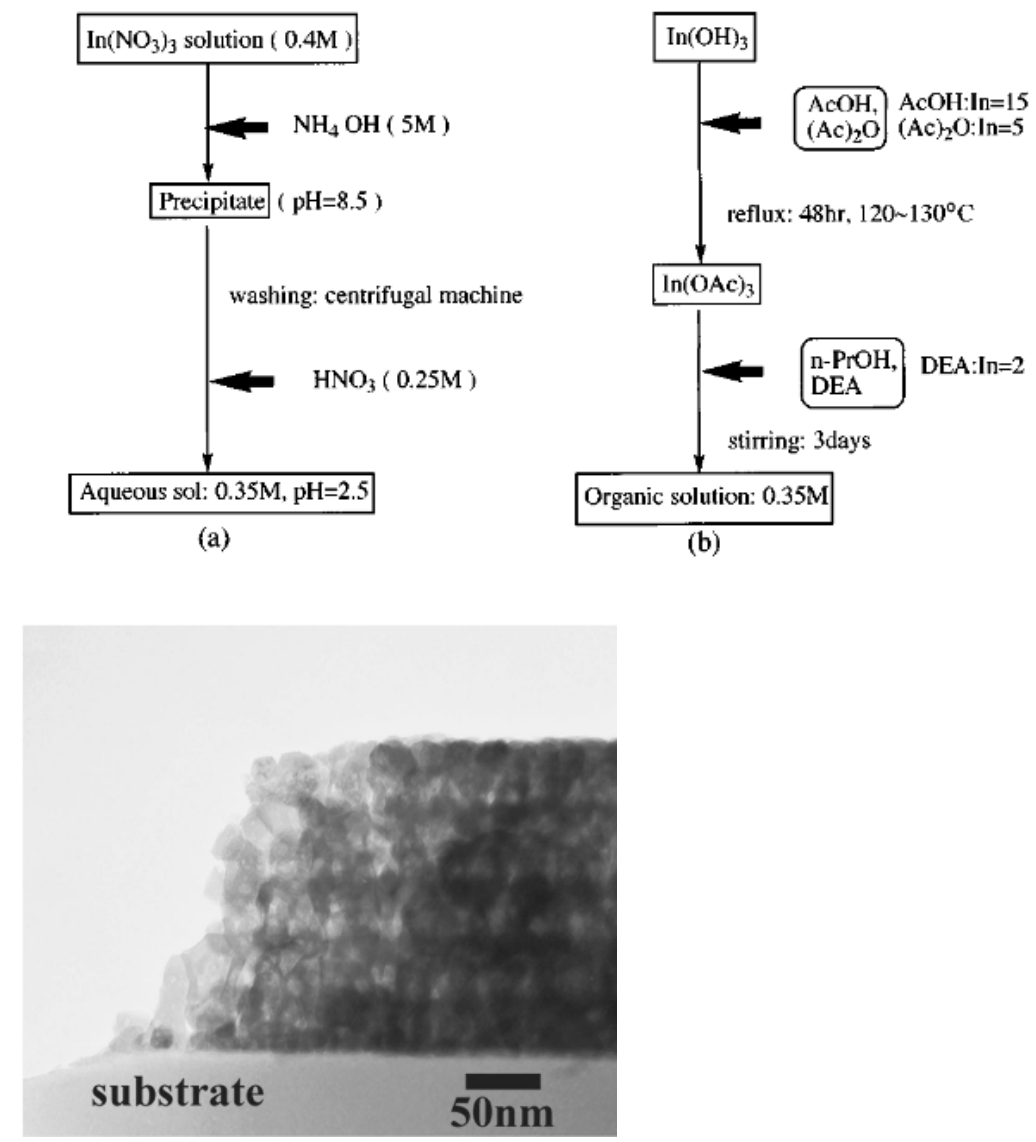

Figure 4 Schematic representation of sol-gel processes for the fabrication of ITO films from a) aqueous and b) organic solution and TEM image of a cross section through an ITO film deposited via an aqueous sol-gel process. ${ }^{[26]}$ (Reproduced with permission. 1997, AIP Publishing LLC)

Despite the excellent opto-electronic properties and well established fabrication methods the use of ITO as transparent electrode involves several drawbacks. Not only the often complex processing, but also the limited availability of Indium ${ }^{[38]}$ render the production of ITO electrodes expensive. In addition, ITO is toxic and environmentally hazardous and the high surface roughness of ITO can be directly related to high leakage currents in OLED devices. ${ }^{[39]}$ Furthermore it has been shown, that oxygen and indium ions tend to diffuse from the ITO electrode into the active layer of a device, which leads to the oxidation and degradation of the active layer material and shortens the lifetime of the devices. ${ }^{[40-44]}$ Therefore indium free 
alternative material are needed for the production of less expensive devices with longer lifetimes.

\subsubsection{Indium free Metal Oxides}

One approach to replace ITO is the use of other metal oxides, which contain less Indium or no Indium at all, with the objective to reduce the toxicity of the material. Therefore multicomponent oxides based on Ga-In-Sn-O (GITO), Zn-In-Sn-O (ZITO), Ga-In-O (GIO) and ZnIn-O (ZIO) have been investigated. ${ }^{[45-47]}$ Although GIO and ZIO based films display conductivities of only some hundreds of $\mathrm{S} \mathrm{cm}^{-1}$, GITO and ZITO systems, grown by metalorganic chemical vapor deposition, show conductivities in the range of $10^{4} \mathrm{~S} \mathrm{~cm}^{-1}$, which are comparable to the conductivity of ITO. In addition, such GITO and ZITO based films were reported to have a lower absorption in the visible range than ITO and considerably higher work functions of $5.4 \mathrm{eV}$ (GITO) to $6.1 \mathrm{eV}$ (ZITO), which are comparable to the work functions of gold $(5.4 \mathrm{eV})$ platinum $(5.7 \mathrm{eV}) .{ }^{[45]}$ Flexible, amorphous Zn-In-Sn-O (ZITO) films fabricated by Zhou et al. ${ }^{[46]}$ showed a sheet resistance lower $20 \mathrm{Ohm} \mathrm{sq}^{-1}$ at $80 \%$ transmittance (FoM $\left.\approx 80\right)$. However, by varying the In content it was shown that the conductivity of $\mathrm{Zn}-\mathrm{In}$-Sn-O systems increase with increasing $\operatorname{In}_{2} \mathrm{O}_{3}$ content, leading to the conclusion that ITO shows the highest conductivity. ${ }^{[48]}$

Completely Indium free, conducting films can also be obtained by doping of $\mathrm{SnO}_{2}$ with Fluorine (F), Niobium (Nb), Tantalum (Ta) or Antimony (Sb). ${ }^{[3,49-56]}$ These films are commonly fabricated by spray pyrolysis, which consists in spraying an aqueous/alcoholic solution of a tin and a dopant salt (e.g. $\mathrm{SnCl}_{4}$ and $\mathrm{NH}_{4} \mathrm{~F}$ ) onto a heated substrate (typically $300{ }^{\circ} \mathrm{C}$ to $500{ }^{\circ} \mathrm{C}$ ), on which thin layers of doped $\mathrm{SnO}_{2}$ are formed. ${ }^{[14]}$ Fluorine doped $\mathrm{SnO}_{2}$ (FTOs) with a film thickness of approximately $1100 \mathrm{~nm}$ display sheet resistances of 2 to $5 \mathrm{Ohm} \mathrm{sq}^{-1}$ at $75 \%$ to $90 \%$ transmittance (FoM:600 to 700) (see Figure 5), which corresponds to a conductivity in 
the range of $10^{3} \mathrm{~S} \mathrm{~cm}^{-1} \cdot{ }^{[51,52,54,56]}$ With a work function of $4.4 \mathrm{eV}^{[53,57]}$ to $5.0 \mathrm{eV}^{[58]}$ these FTO films are suitable for the integration in solar cell and LED devices. Even if the conductivity of FTO films is about one order of magnitude lower than the conductivity of ITO, FTO is widely used as electrode in solar cells ${ }^{[59]}$ and $\operatorname{LEDs}^{[53]}$, as it is considerably less expensive than ITO $^{[3,60]}$ and shows excellent thermal and chemical stability ${ }^{[3,54,60]}$.
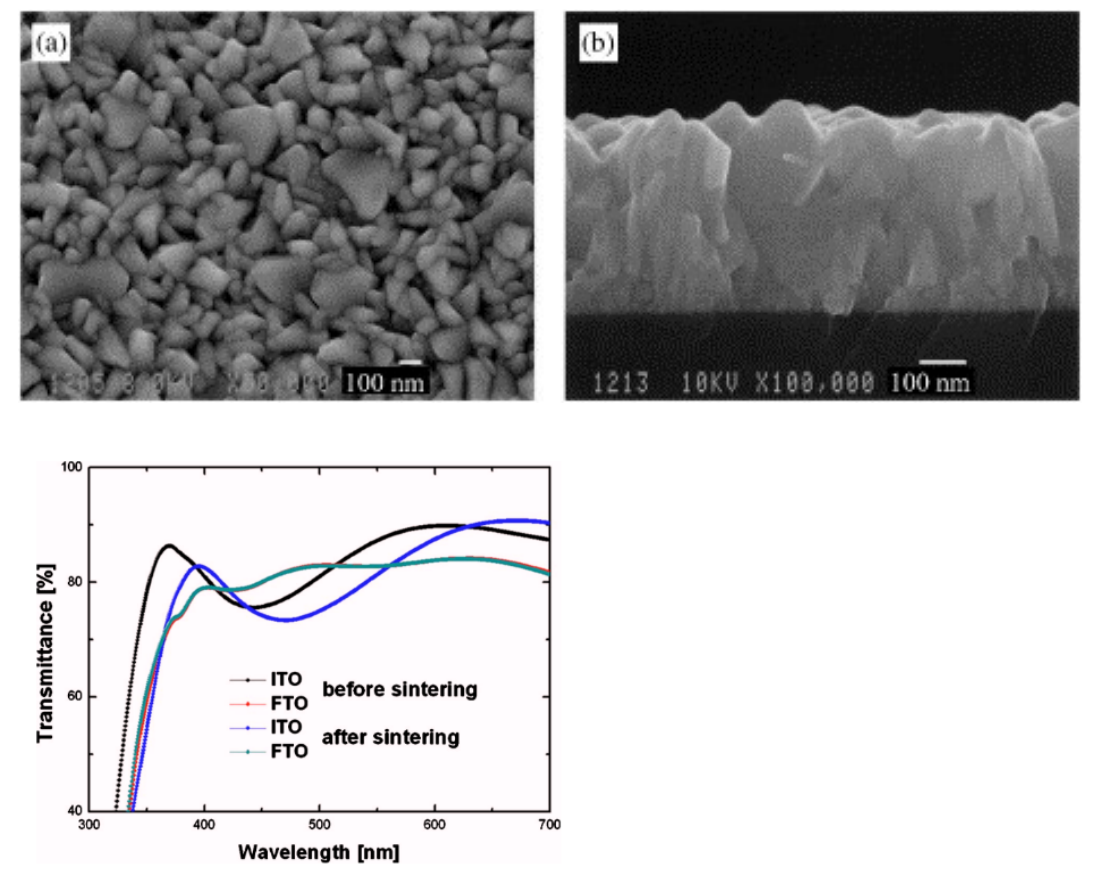

Figure 5 FE-SEM images of (a) the surface morphology and (b) cross-sectional image of $\mathrm{SnO}_{2}: \mathrm{F}$ film before the heat treatment ${ }^{[54]}$ (Reproduced with permission. 2004, Elsevier) and c) transmittance in the visible regime of ITO and FTO films ${ }^{[59]}$ (Reproduced with permission. 2010, AIP Publishing LLC)

Another family of metal oxides that displays very promising opto-electronic properties are titanium based oxides in the anatase phase. Films made of $\mathrm{TiO}_{2}$ doped with Fluorine (F), Niobium (Nb), Tantalum (Ta) or Tungsten (W) show conductivities in the range of $10^{3} \mathrm{~S} \mathrm{~cm}^{-1}$ and transparencies of about $95 \%{ }^{[61]}$ However, these highly conducting and transparent films 
were produced by epitaxial growth, which makes them too expensive for broad base application. $^{[61-64]}$

Yet another promising approach to replace ITO is the development of transparent electrodes based on the non-toxic and abundant zinc oxide. $\mathrm{ZnO}$ displays good opto-electronic properties and upon doping with Ga or Al zinc oxide based electrodes (GZO and AZO, respectively) can show charge carrier densities of up to $10^{21} \mathrm{~cm}^{-3}[65]$, which is comparable to the charge carrier density in ITO. Thin $\mathrm{ZnO}$ films can be fabricated by various physical and chemical methods, ranging from vapor deposition ${ }^{[65]}$, sputtering ${ }^{[66]}$ or spray pyrolysis ${ }^{[67]}$ to sol-gel processing ${ }^{[68-}$ 70]. The most employed method is magnetron sputtering, which allows the fabrication of polycrystalline Aluminum doped $\mathrm{ZnO}$ (AZO) films with a sheet resistance of $100 \mathrm{Ohm} \mathrm{sq}^{-1}$ at $95 \%(90 \%)$ transmittance (FoM=35 and FoM=73, respectively) and a conductivity up to 675 $\mathrm{S} \mathrm{cm}^{-1}\left(1400 \mathrm{~S} \mathrm{~cm}^{-1}\right){ }^{[68,71,72]}$ OLED devices with such AZO electrodes displayed comparable performances as ITO reference devices. ${ }^{[72]}$ Furthermore it was shown, that AZO electrodes can be deposited onto flexible polyethersulfone substrates via magnetron sputtering using substrate temperatures of $200{ }^{\circ} \mathrm{C}$, which resulted $250 \mathrm{~nm}$ thick, homogeneous films with conductivities of $2000 \mathrm{~S} \mathrm{~cm}^{-1}$ at $90 \%$ transmittance. ${ }^{[73]}$ However, it was demonstrated that Zinc ions tend to diffuse from the electrode into the $\mathrm{Alq}_{3}$ emissive layer, which is comparable to the well documented diffusion of Indium ions from ITO into the active layer. ${ }^{[72]}$ Furthermore, the work function of untreated $\mathrm{ZnO}$ is relatively low with approximately $4.3 \mathrm{eV}$, which creates injection barriers to most materials in organic electronic devices. Therefore the $\mathrm{ZnO}$ work function has to be modified by surface treatments for the application of $\mathrm{ZnO}$ electrodes in devices. ${ }^{[70]} \mathrm{In}$ addition, $\mathrm{ZnO}$ is very sensitive to heat and humidity, which induce rapid degradation of the opto-electronic properties. ${ }^{[48,60,74]}$

\subsubsection{Conclusion}


In summary, metal oxide thin films display extremely high conductivities in the range of $10^{4} \mathrm{~S}$ $\mathrm{cm}^{-1}$ with excellent transparencies of higher than $85 \%$ in the visible range and work functions in the range of $4.3 \mathrm{eV}$ to $6.1 \mathrm{eV}$, which makes them attractive as transparent electrode material. However, they are not suitable for flexible applications, owing to their brittle nature. Another common drawback of metal oxide based transparent electrodes is the often complex processing at high temperatures, which renders the production expensive and limits the compatibility with plastic substrates. In addition, some of the best performing metal oxides contain toxic and rare elements, e.g. indium in indium tin oxide. The non-toxic and solution processable $\mathrm{ZnO}$, however, shows a very low work function and low resistance to heat and humidity. In addition, when integrated in devices, certain metal ions such as zinc or indium tend to diffuse into the active layer, which limits the lifetime of the optoelectronic devices.

\subsection{Metallic Electrodes}

\subsubsection{Thin Metal Films}

Metals are known for their high conductivity, which results from the free electron character of the valence electrons. At the same time bulk metals are famous for their colored and shiny appearance, which indicates that metals absorb in the visible range and are therefore not transparent. Therefore only ultra-thin metal films with a thickness below $10 \mathrm{~nm}$ become transparent. However, with decreasing thickness the resistivity of metal films increases due to electron scattering at the surface and grain boundaries. ${ }^{[75]}$ Hence, a compromise between sufficient transparency and conductivity must be found for the fabrication of transparent metal electrodes.

Silver (Ag), Gold (Au), Chromium (Cr), Nickel (Ni) and Platinum (Pt) films and metal bi-layers with the thickness of some nanometers expose both a high conductivity and a high transparency and can compete with ITO films in terms of their opto-electronic performance. ${ }^{[76-79]}$ O'Connor 
et al. ${ }^{[80]}$ reported, that a photovoltaic cell with a $9 \mathrm{~nm}$ thick evaporated silver $(\mathrm{Ag})$ electrode displayed an even slightly higher efficiency than the ITO reference cell (see Figure 6). Thin films evaporated from a Ca:Ag blend were reported to display a sheet resistance of $27 \mathrm{Ohm} \mathrm{sq}^{-}$ ${ }^{1}$ at $93 \%$ transmittance $(\mathrm{FoM} \approx 190)^{[81]}$ and OPV devices based on these Ca:Ag electrodes showed a higher efficiency than the ITO reference device, but underwent rapid degradation. Another approach was presented by Ghosh et al. ${ }^{[82]}$, who replaced the ITO electrode by a semitransparent, $8 \mathrm{~nm}$ thick $\mathrm{Cu}-\mathrm{Ni}$ bilayer $\left(R_{s}=16 \mathrm{Ohm} \mathrm{sq}^{-1}, T=57 \%\right.$, FoM=36), which resulted in a device efficiency of $76 \%$ as compared to the ITO reference device. The relatively high efficiency despite the low transparency of the electrode was explained by the high reflectance of the $\mathrm{Cu}-\mathrm{Ni}$ layer, which leads to a microcavity effect and a higher light harvesting efficiency in the device. Despite the good performance in devices, the application of ultra-thin metal films as electrodes faces problems due the fragility and the relatively high surface roughness of the thin metallic films.
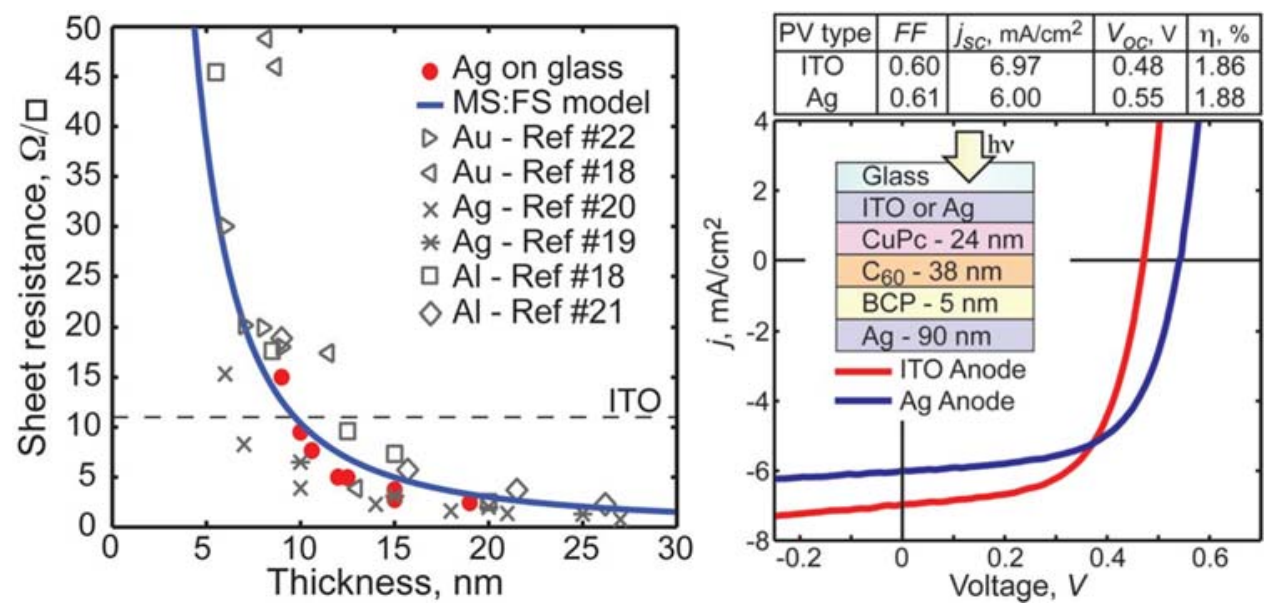

Figure 6 Sheet resistance versus film thickness for thin $\mathrm{Ag}, \mathrm{Al}$ and $\mathrm{Au}$ films compared to the sheet resistance of ITO (left) and $\mathrm{J}-\mathrm{V}$ characteristics of OPV devices under $106 \mathrm{~mW} \mathrm{~cm} \mathrm{c}^{-1}$ illumination with $9 \mathrm{~nm} \mathrm{Ag}$ and $150 \mathrm{~nm}$ ITO anodes $^{[80]}$ (Reproduced with permission. 2008, AIP Publishing LLC) 


\subsubsection{Metal Grids}

A simple and cheap way to produce transparent conducting electrodes from various metals is the fabrication of metal nanoscale grids by nanoimprint lithography (see Figure 7). By varying the thickness and the pattern size of the grid the conductivity and transmittance of the electrode can be tuned. However, if the pattern dimensions are in the range of the wavelength of visible light, interference effects, which can affect the transmittance of the electrode, have to be taken into account. ${ }^{[83]}$ Furthermore it has been demonstrated that the discontinuous character of the electrode induces an increase in resistance in the neighboring semiconducting layer, which is why different criteria than the commonly used FoM should be considered for the evaluation of metal grid electrodes. ${ }^{[84]}$ Upon optimization of the pattern dimensions, films with a sheet resistance between $5 \mathrm{Ohm} \mathrm{sq}^{-1}$ to $24 \mathrm{Ohm} \mathrm{sq}^{-1}$ with $70 \%$ to $80 \%$ transmittance (FoM between 60 and 190) in the visible range can be obtained. ${ }^{[55-87]}$ Photovoltaic cells based on such metal grid electrodes exhibited the same performance as ITO reference cells. ${ }^{[85-87]}$
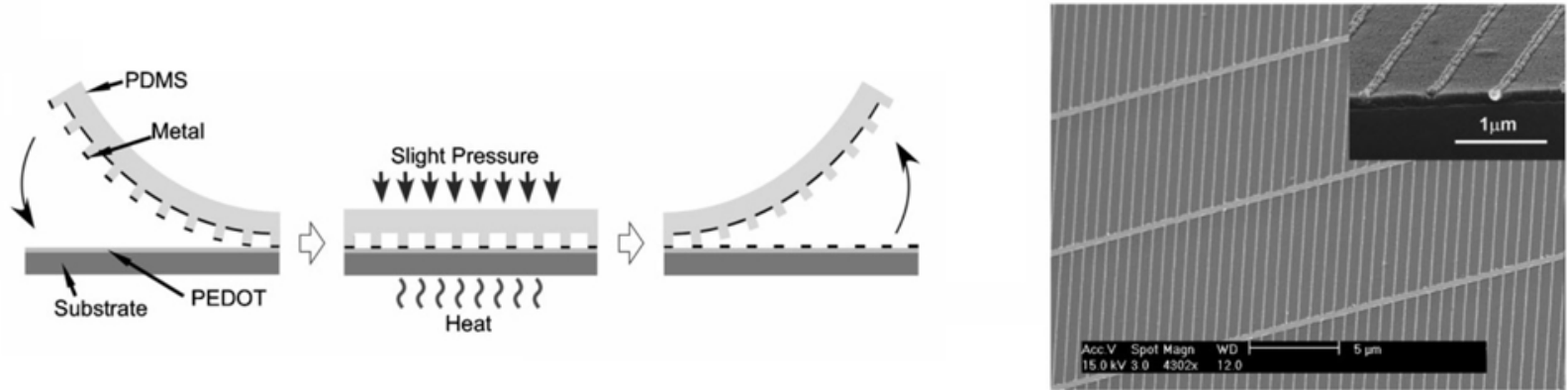

Figure 7 Scheme of the fabrication of nano patterned $\mathrm{Cu}$ by nano imprinting using a PDMS stamp and SEM image of the $\mathrm{Cu}$ electrode on a PEDOT:PSS coated glass substrate ${ }^{[86]}$ (Reproduced with permission. 2016, Royal Society of Chemistry)

By using a combination of soft imprint lithography and solution processing (see Figure 8) Sciacca et al. ${ }^{[87]}$ fabricated patterned Ag electrodes, which showed a higher conductivity than 
thermally evaporated networks. Another approach to fabricate Ag nanogrids from solution was presented by Kang et al. ${ }^{[89]}$, who deposited $\mathrm{Ag}$ nanoparticles into nanogrid templates via capillary assembly. The obtained electrodes displayed a sheet resistance of $15 \mathrm{Ohm} \mathrm{sq}^{-1}$ and an optical transmittance of $85 \%($ FoM=148).
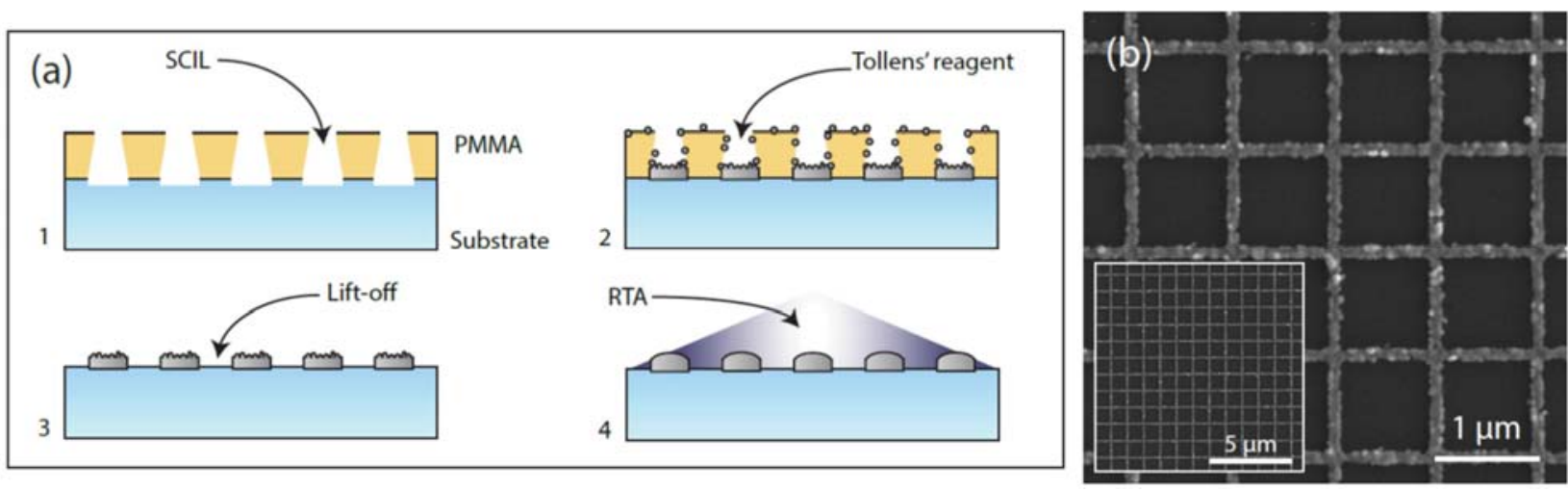

Figure 8 a) Scheme for the fabrication of solution grown Ag nano structures and b) SEM image of the solution grown Ag network before rapid thermal annealing (RTA) ${ }^{[88]}$ (Reproduced with permission. 2015, John Wiley and Sons)

Only recently printing methods, such as electrohydrodynamic printing, were developed, which allow the fabrication of $\mathrm{Ag}$ and $\mathrm{Au}$ nanogrids with line widths down to $80 \mathrm{~nm}$ (see Figure 8). ${ }^{[90,91]}$ These electrodes display very high transparencies of $94 \%$ to $97 \%$ at $8 \mathrm{Ohm} \mathrm{sq}^{-1}$ to 20 $\mathrm{Ohm} \mathrm{sq}^{-1}$ sheet resistance (FoM: 615 to 750 ), respectively. ${ }^{[90]}$

A top down method for the fabrication of micro structured metal electrodes consists in the patterning of thin metal films using three beam direct laser interference patterning ${ }^{[92]}$. With this technique $\mathrm{Al}$ electrodes with sheet resistance of $25 \mathrm{Ohm} \mathrm{sq}^{-1}$ to $50 \mathrm{Ohm} \mathrm{sq}^{-1}$ at $81 \%$ transmittance (FoM:35 to 70) were obtained (see Figure 9c). ${ }^{[93]}$

To summarize, nanopatterned metal films display a very good opto-electronic performance, are mechanically and chemically stable, are compatible with flexible substrates and can be produced cost efficiently on a large scale. Therefore, the main drawback for their application in 
devices is their extremely high surface roughness, which can render it difficult to ensure good contact between the electrode and the active layer.
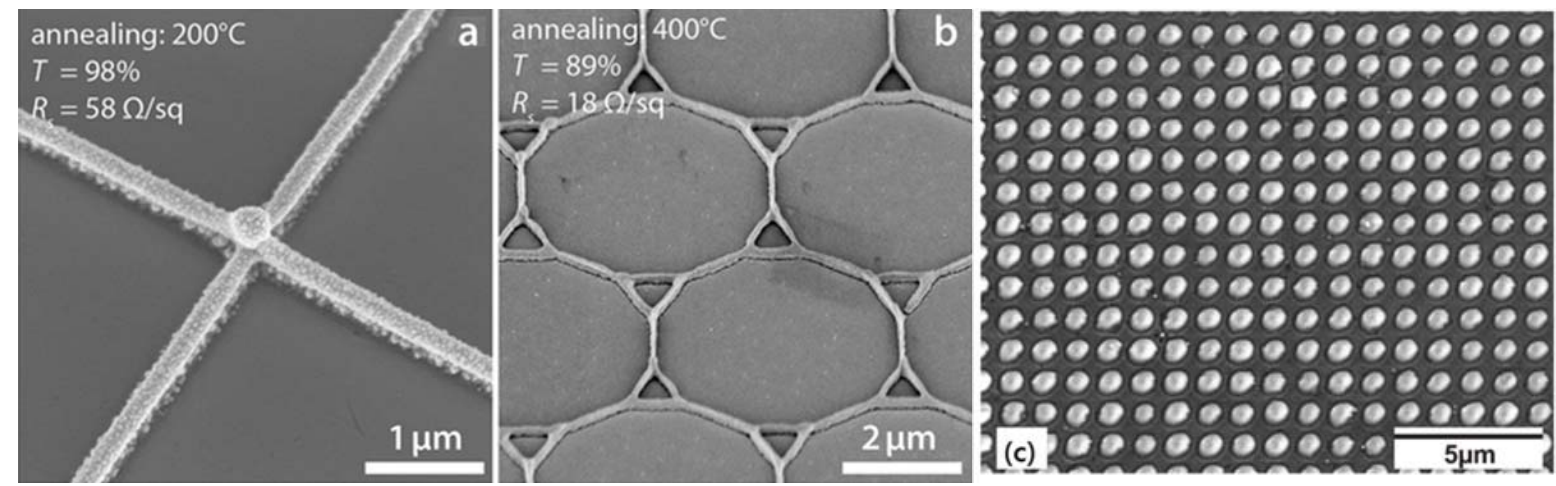

Figure 9 a), b) demonstration of NanoDrip printing ${ }^{[90]}$ (Reproduced with permission. 2015, John Wiley and Sons) c) SEM image of a laser patterned Al film with a spatial pattern period of $\Lambda=1.7 \mu \mathrm{m}^{[93]}$

\subsubsection{Metal Nanowires}

Another approach to transparent, metallic electrodes is the fabrication of thin films from metal nanowires. ${ }^{[4]}$ The nanowires which are commonly used for this purpose display diameters smaller than $100 \mathrm{~nm}$ and a length of several micrometers, as it was shown that the use of nanowires with high aspect ratios improves the mechanical stability of the films. Most of the nanowires are made of silver or copper, as these nanowires can be easily synthesized in solution via the reduction of silver nitrate or of copper ion complexes, respectively. ${ }^{[94-100]}$ The obtained dispersions can then be directly coated onto a substrate using roll-to-roll techniques, which results in flexible films with good opto-electronic properties, such as a sheet resistance of about $10 \mathrm{Ohm} \mathrm{sq}^{-1}$ to $13 \mathrm{Ohm} \mathrm{sq}^{-1}$ at $85 \%$ to $90 \%$ transmittance (FoM of 190 to 280$){ }^{[2,101,102]} \mathrm{OPV}$ devices based on such Ag nanowire electrodes showed very similar performance to the ITO reference devices. ${ }^{[101]}$ Lee et al. ${ }^{[103]}$ reported that the conductivity of Ag nanowire electrodes can be enhanced by using extra-long Ag nanowires with a length of up to $500 \mu \mathrm{m}$. Furthermore 
it was demonstrated that the electronic properties of those Ag wire electrodes (sheet resistance of $9 \mathrm{Ohm} \mathrm{sq}^{-1}$ at $90 \%$ transmittance, FoM=387) were maintained upon stretching of the electrodes up to $250 \%$ elongation, which allowed the fabrication of highly flexible devices.

Owing to their metallic character, the metal nanowires are highly conducting and the main resistivity of the nanowire films stems from the resistivity of the inter-wire junctions. ${ }^{[104]}$ Therefore, several approaches were developed to increase the film conductance by improving the wire to wire junction contact. The most common method consists in thermal annealing of the films. ${ }^{[101]}$ Also mechanical pressing of the metal nanowire films has been shown to decrease the sheet resistance. ${ }^{[104]}$ However, pressing brings about a broadening of the wire diameter which leads to a decrease of the transparency of the films. Another approach was presented by $\mathrm{Hu}$ et al. ${ }^{[104]}$, who reported that the junction resistance in Ag nanowire films was drastically decreased from $10 \mathrm{GOhm}$ to $450 \mathrm{Ohm}$ upon deposition of a thin gold layer on the wire network (see Figure 10).
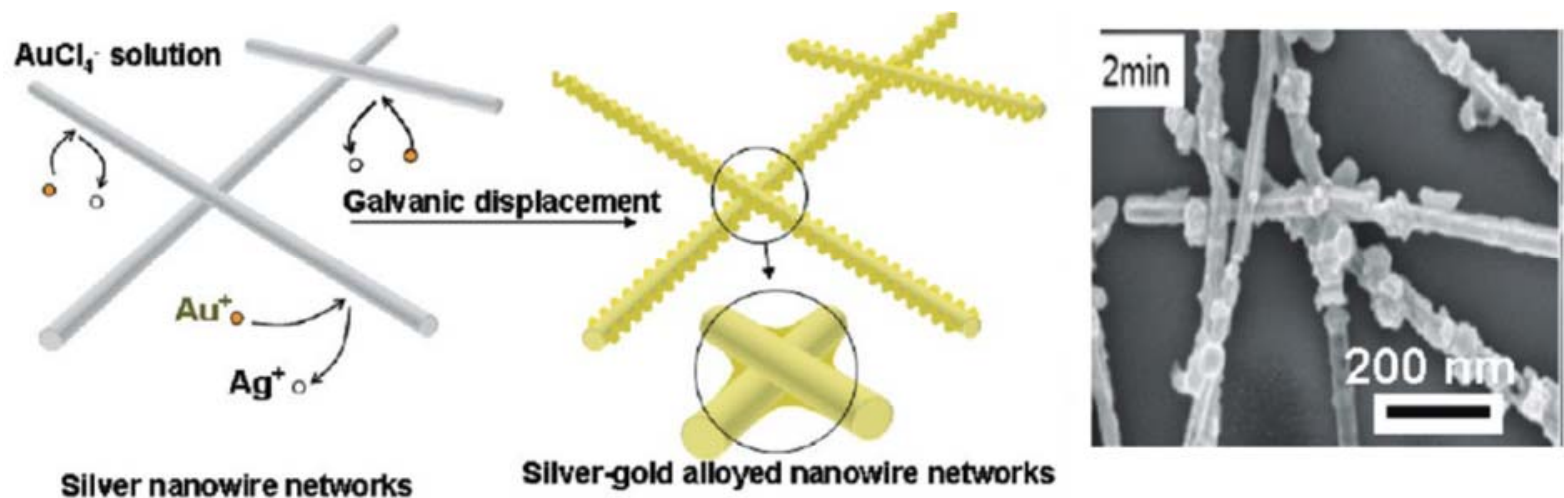

Silver nanowire networks

Figure 10 Scheme for the galvanostatic deposition of Au on a Ag nanowire network and TEM images of the obtained AgNW-Au film ${ }^{[104]}$ (Reproduced with permission. 2010, American Chemical Society) 
Furthermore, it was shown that the resistivity of Ag nanowire films can be decreased by immersion of the films in a graphene oxide dispersion, which was attributed to a decrease of the contact resistance between the single Ag wires due to the graphene oxide wrapping around the wire junctions (see Figure 11). ${ }^{[105]}$ A similar approach was presented by Stapleton et al. ${ }^{[106]}$, who fabricated solution processed films of inter-woven Ag nanofibers and carbon nanotubes which displayed a sheet resistance of $4 \mathrm{Ohm} \mathrm{sq}^{-1}$ to $24 \mathrm{Ohm} \mathrm{sq}^{-1}$ at $82 \%$ transmittance (FoM=75 to 450). In these films the carbon nanotubes were found to wrap around the silver wires, which created conductive interconnections and increased the mechanical stability of the film.
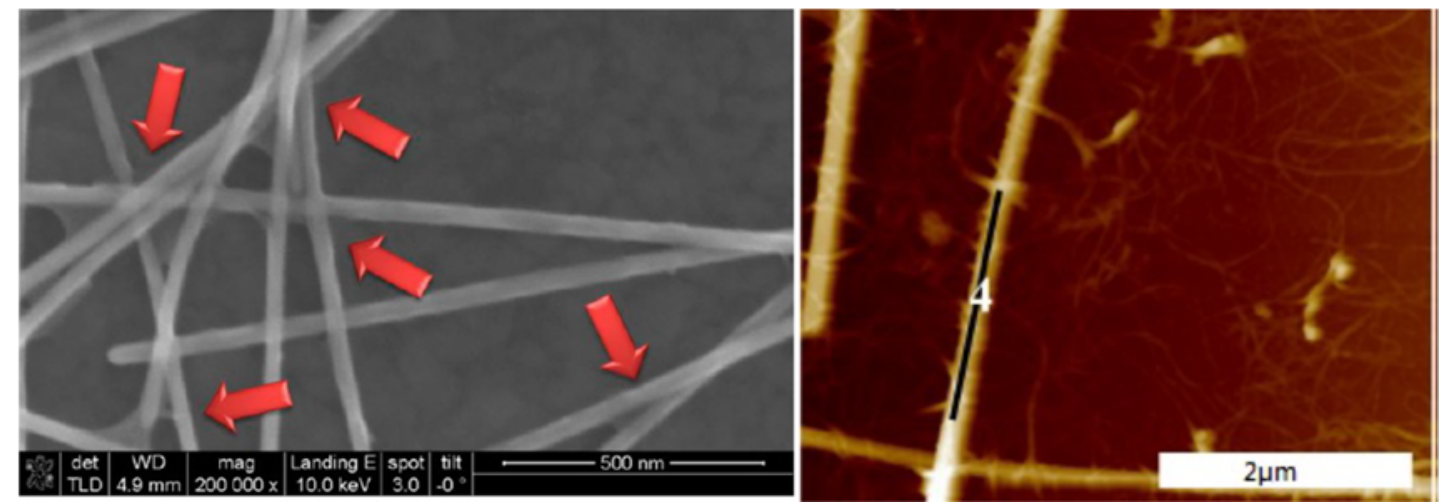

Figure 11 SEM image of the Ag nanowire - graphene oxide film ${ }^{[105]}$ (left) and AFM image of the Ag nanowire - carbon nanotube composite film. ${ }^{[106]}$

An alternative fabrication method for metal nanowires is electrospinning, which allows to produce nanowires with extremely high aspect ratios and from different metals. By evaporating copper on an electro-spun template network of soluble polymer fibers Hsu et al. ${ }^{[107]}$ obtained transparent $\mathrm{Cu}$ films with a sheet resistance of $9 \mathrm{Ohm} \mathrm{sq}^{-1}$ at $90 \%$ transmittance $(\mathrm{FoM}=387)$. Electrodes with an even lower sheet resistance of $0.36 \mathrm{Ohm} \mathrm{sq}^{-1}$ and a high transmittance of $92 \%($ FoM $>11000)$ were obtained by combining an $\mathrm{Ag}$ nanowire network with meso-scale $\mathrm{Cu}$ wires of 1 to $50 \mu \mathrm{m} \cdot{ }^{[108]}$ Photovoltaic cells with $\mathrm{Cu}$ nanowire electrodes (sheet resistance of 50 Ohm sq ${ }^{-1}$ at $90 \%$ transmittance, FoM=70), fabricated via annealing of electro-spun 
polymer/Cu-precursor fibers, reached efficiencies of $3 \%$, which was comparable to the efficiency of cells with ITO electrodes. ${ }^{[109]}$

In analogy to the nano-patterned metal electrodes, the main drawback of the highly conducting and transparent metal nanowire films is their high surface roughness, which hinders good contact of the film to the active layer.

\subsubsection{Conclusion}

There are several approaches to take advantage of the extremely high conductivity of metals for the fabrication of metallic transparent electrodes, such as the preparation of nanometer thin films, the nanopatterning of metallic films into grids or the use of metallic nanowire networks. Such metal electrodes can display extremely low sheet resistances of below $10 \mathrm{Ohm} \mathrm{sq}^{-1}$ at a transmittance of $90 \%$ or higher. In addition, the metallic nanostructures display high chemical and mechanical stability, are compatible with flexible substrates and can be produced cost efficiently on a large scale via solution processing or lithography. However, they display a high surface roughness which prevents good contact to the neighboring layers in a device.

\section{Organic Conducting Materials}

\subsection{Graphene and Carbon Nanotubes}

Graphene is a monolayer of graphite in which $\mathrm{sp}^{2}$ - hybridized carbon atoms form a 2dimensional honeycomb structure. This bonding situation results in a $2 \mathrm{D}$ delocalization of electrons which enables scattering free in plane transport of the charge carriers. ${ }^{[38]}$ This results in an extremely high charge carrier mobility of about $210^{5} \mathrm{~cm}^{2} \mathrm{Vs}^{[110]}$ and a very low theoretical sheet resistance of about $30 \mathrm{Ohm} \mathrm{sq}^{-1}{ }^{[110]}$ for the single graphene sheets. Therefore, 
graphene is potentially interesting as material for transparent electrode applications. However, the experimentally measured sheet resistance of graphene is in the range of several hundreds of Ohms per layer. This discrepancy between the theoretical sheet resistance and the experimentally measured value can be explained by defects and grain boundaries in the graphene sheets, which represent energy barriers for the charge transport. In macroscopic graphene films, which are composed of several graphene sheets, the resistivity is even higher due to the high resistivity of the sheet to sheet contacts. ${ }^{[38]}$

The fabrication of graphene using the simple scotch peel method has attracted much attention, however, this method is not suitable for the production of graphene on large scales. Therefore, the graphene sheets used for the fabrication of conducting electrodes are either synthesized by chemical vapor deposition (CVD) or from large organic precursor molecules.

CVD grown graphene shows a sheet resistance of $230 \mathrm{Ohm} \mathrm{sq}^{-1}$ or higher, a maximum transmittance of $91 \%$ and is highly transparent in the infra-red regime. ${ }^{[110]}$ The specific electrical and optical properties, however, depend on the synthesis conditions during the CVD process. It was found, that, for instance, the thickness of the graphene films increased with increasing process temperature. Choe et al. ${ }^{[111]}$ reported, that graphene films grown at $1000{ }^{\circ} \mathrm{C}$ displayed a sheet resistance of $600 \mathrm{Ohm} \mathrm{sq}^{-1}$ at a transmittance of $87 \%(\mathrm{FoM}=4)$, whereas films grown at $800{ }^{\circ} \mathrm{C}$ were thinner and showed a sheet resistance of $1700 \mathrm{Ohm} \mathrm{sq}^{-1}$ at $91 \%$ transmittance $(\mathrm{FoM}=2)$. The sheet resistance of CVD graphene sheets can be reduced by chemical doping with $\mathrm{AuCl}_{3}, \mathrm{HNO}_{3}$ or $\mathrm{SOCl}_{2} \cdot{ }^{[112-114]}$ Kim et al. ${ }^{[113]}$ observed a drop in the sheet resistance of graphene of $77 \%$ upon doping with $\mathrm{AuCl}_{3}$, resulting in films with a sheet resistance of $150 \mathrm{Ohm} \mathrm{sq}^{-1}$ at $87 \%$ transmittance $(\mathrm{FoM}=17)$. This trend was confirmed by Park et al. ${ }^{[112]}$ who found, that the doping of graphene electrodes with $\mathrm{AuCl}_{3}$ lead to a significant increase in the power conversion efficiency of OPV devices. More recently, Chen et al. ${ }^{[115]}$ presented carbon enclosed CVD as novel method for the synthesis of graphene, by which 
graphene sheets with a sheet resistance of $5 \mathrm{Ohm} \mathrm{sq}^{-1}$ at $93 \%$ transmittance $(\mathrm{FoM}=1020)$ were obtained.

Transparent graphene films can also be obtained from large organic precursor molecules, as reported by Wang et al. ${ }^{[116]}$. By thermal annealing of hexadodecyl-substituted superphenalene (see Figure 12) at $1100^{\circ} \mathrm{C}$ on a quartz substrate under argon atmosphere, graphene films of 4 $\mathrm{nm}$ and $30 \mathrm{~nm}$ thickness were obtained, which displayed a conductivity of $206 \mathrm{~S} \mathrm{~cm}^{-1}\left(R_{\mathrm{S}}(4\right.$ $\left.\mathrm{nm})=12000 \mathrm{Ohm} \mathrm{sq}^{-1}, R_{s}(30 \mathrm{~nm})=1600 \mathrm{Ohm} \mathrm{sq}^{-1}\right)$ and a transmittance of $90 \%$ and $55 \%$ (at $500 \mathrm{~nm}$ ), respectively, which corresponds to a FoM of smaller than 1. However, it was shown that the conductivity of the obtained graphene was strongly affected by the nature of the substrate, such that by using $\mathrm{SiO}_{2} / \mathrm{Si}$ substrates instead of quartz substrates the conductivity of the graphene sheets was increased to $2000 \mathrm{~S} \mathrm{~cm}^{-1}$.

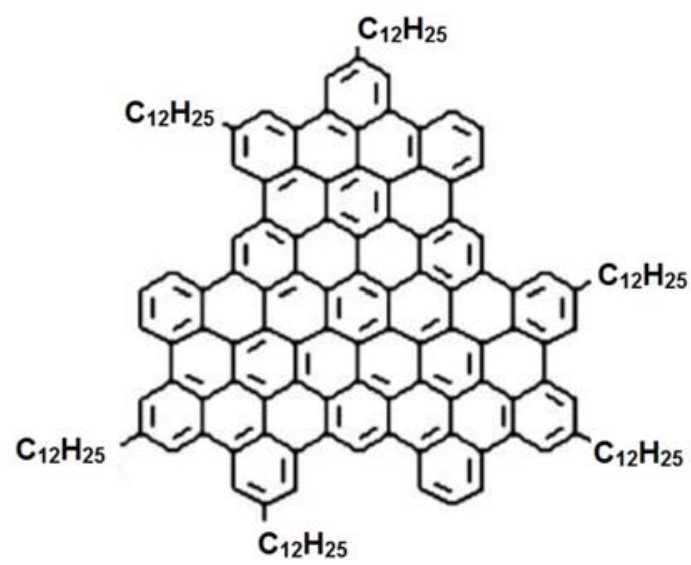

Figure 12 Chemical structure of hexadodecyl-substituted superphenalene used as graphene film precursor $^{[116]}$ (Reproduced with permission. 2008, John Wiley and Sons)

Solution processing of graphene has been proven to be difficult, owing to its very stable $\pi$-bond system, which leads to strong inter-plane interactions and renders graphene indispersible. One possibility to exfoliate and disperse graphene in a solvent is by functionalization, such as oxidation. However, graphene oxide shows a high resistivity, as the large structure of 
delocalized electrons is destroyed. Therefore, oxidized graphene films have to be reduced again before being used as electrodes. Films produced from functionalized graphene can show high transparencies, but due to incomplete reduction even post treated films display very high resistivities of $800 \mathrm{Ohm} \mathrm{sq}^{-1}$ to $5 \mathrm{kOhm} \mathrm{sq}^{-1}$ or higher. ${ }^{[117,118]}$ Thus, OPV devices with electrodes fabricated by solution processing of graphene oxide displayed poorer performance than ITO reference devices. ${ }^{[117,118]}$

Independently of the synthesis method and properties of the graphene, most devices with transparent graphene electrodes can hardly compete with ITO reference devices. This is not only related to the opto-electronic performance of the graphene sheets, but also to the electrode - active layer interface. ${ }^{[12,119,120]}$ On one hand, the graphene layers are rough and very hydrophobic, which leads to inhomogeneities with the adjacent hole injecting layer, such as PEDOT:PSS. On the other hand, graphene has a very low work function with respect to the active layer materials, which leads to poor charge collection and a high electrode resistance. Thus, the surface of graphene electrodes has to be modified, for instance by the deposition of $\mathrm{MoO}_{3}$ layers ${ }^{[19,120]}$, in order to increase the device performance.
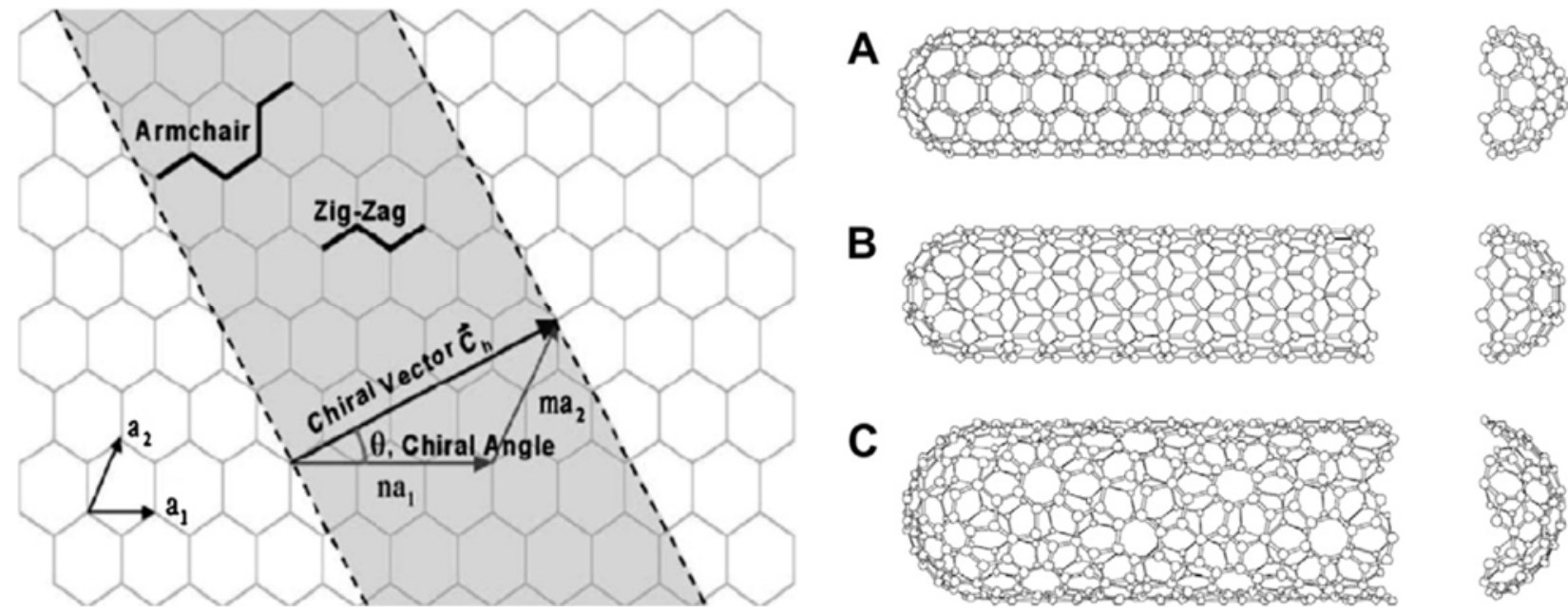

B
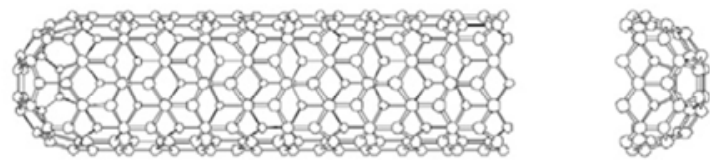

C
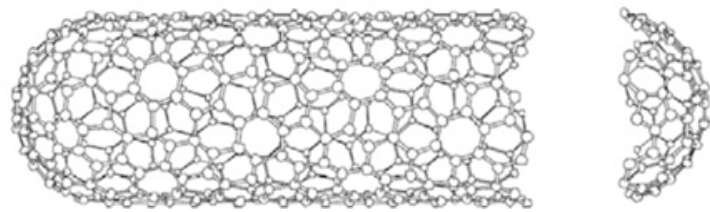

Figure 13 Scheme of a carbon nanotubes with different chiralities ${ }^{[121]}$ (Reproduced with permission. 2010, Elsevier) 
Another type of carbon nanostructures, composed of $\mathrm{sp}^{2}$ hybridized carbon and very similar to graphene, are carbon nanotubes (CNTs). CNTs are artificial allotropes of carbon and can be described as graphene sheets, which are rolled up into cylinders with an approximate diameter of one nanometer and whose ends are partly closed by fullerene like structures (see Figure 13). With an extremely high aspect ratio of up to 1000 , CNTs are thought of as one dimensional material. However, CNTs are heterogeneous materials, which show differences in structure and opto-electronic properties (see Figure 14). ${ }^{[121-123]}$ One of the main structural difference for CNTs is the number of $\mathrm{sp}^{2}$ carbon sheets that form one single tube. There are CNTs which consist of only one rolled up graphene layer, called single walled carbon nanotubes (SWCNTs), and CNTs with several graphene layers, which interact via van der Waals forces, called multi walled carbon nanotubes (MWCNTs). Furthermore, the hexagonal network of the $\mathrm{sp}^{2}$ carbon sheets can be arranged in different ways around the tube axis, which is described by the so called tube chirality (see Figure 13). ${ }^{[121,122]}$

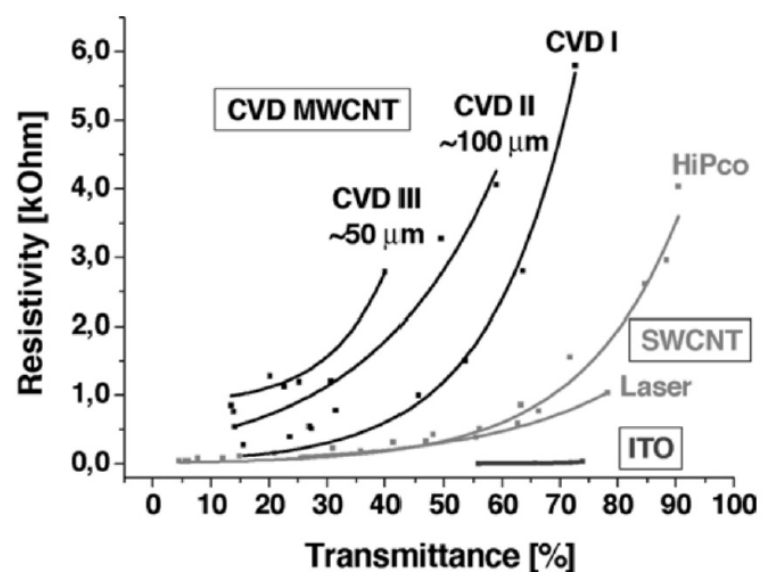

Figure 14 Resistivity vs. transmittance of different spray coated MWCNT and SWCNT films and ITO. ${ }^{[123]}$ (Reproduced with permission. 2005, Elsevier) 
Depending on their chirality CNTs display either semiconducting or metallic behavior. Metallic CNTs show similar band structures as metals and very high conductivities up to $10^{5} \mathrm{~S} \mathrm{~cm}^{-1}$. However, just as for bulk metals, the absorption of metallic CNTs in the optical range is very high, whereas semiconducting CNTs are transparent. Furthermore, the optical transitions vary with the tube diameter, as the tube diameter is inversely proportional to the band gap of the CNTs. ${ }^{[124]}$ As in most production processes none of the three chiralities is formed preferentially, customary CNT samples contain semiconducting and metallic CNTs in the ratio 2:1. However, the fabrication of films with uniform electrical and optical properties requires CNTs batches, which are monodisperse in electronic type and diameter. Consequently, much effort is made to efficiently separate CNTs regarding to their electrical properties and their diameter. ${ }^{[121,124-128]}$ Another challenge working with CNTs is their limited dispersability, caused by strong van der Waals forces between the tubes, which renders the fabrication of homogeneous thin films difficult. Attempts to disperse CNTs by sonication showed, that upon sonication the nanotubes tend to break into shorter pieces, which lowers the conductivity of the obtained films. ${ }^{[129]}$ Another approach is to disperse CNTs by non-covalent functionalization of the CNT surface with surfactants, such as sodium dodecyl sulfate (SDS), or polymers, such as poly(3hexylthiophene) (P3HT), poly(vinyl pyrrolidone) (PVP) or sodium carboxymethyl cellulose $(\mathrm{CMC})^{[103,129,130]}$. However, after film deposition these molecules are often difficult to remove. Despite the difficult processing, CNTs are of interest for the fabrication of transparent electrodes, owing to their extremely high conductivity and a suitable work function in the range of $4.8 \mathrm{eV}$ to $5.1 \mathrm{eV} \cdot{ }^{[131,132]}$

The fabrication of flexible transparent electrodes from double walled CNTs (DWCNTs) via solution processing was reported by Imazu et al. ${ }^{[133]}$. Upon optimization of the key parameters, such as the DWCNT length, their dispersion and the concentration of the dispersant CMC, films with a sheet resistance of $320 \mathrm{Ohm} \mathrm{sq}^{-1}$ at $94 \%$ transmittance $(\mathrm{FoM}=17)$ and a surface roughness $R_{q}$ of 8 to $10 \mathrm{~nm}$ were obtained. Electrodes made from SWCNTs via solution 
processing with $\mathrm{CMC}$ and doped by post-treatment with nitric acid, displayed a sheet resistance of $50 \mathrm{Ohm} \mathrm{sq}^{-1}$ and $150 \mathrm{Ohm} \mathrm{sq}^{-1}$ at $77 \%$ and $85 \%$ average transmittance $(400 \mathrm{~nm}-1800 \mathrm{~nm})$ and a FoM of 27 and 15, respectively. ${ }^{[129]}$ The percolation threshold in these films was calculated to be extremely low with $0.011 \mu \mathrm{g} \mathrm{cm}^{-2}$ and upon integration into an OPV device with a P3HT:PCBM active layer efficiencies of $3.1 \%$ were reached. ${ }^{[129]}$

Kaskela et al. ${ }^{[134]}$ reported the fabrication of transparent SWCNT films by aerosol chemical vapor deposition, in which SWCNT are formed upon the thermal decomposition of ferrocene vapor in carbon monoxide atmosphere. After chemical doping with $\mathrm{HNO}_{3}$ the transparent electrodes showed a sheet resistance of $110 \mathrm{Ohm} \mathrm{sq}^{-1}$ at $90 \%$ transmittance $(\mathrm{FoM}=32)$. Similar transparent electrodes fabricated by aerosol chemical vapor deposition were successfully integrated in OPVs and perovskite solar cells. ${ }^{[135,136]}$ However, these OPV devices showed only low efficiencies of $1.9 \%{ }^{[135]}$

The low efficiency of devices with pure CNT electrodes can be explained by the high surface roughness and porosity of CNT electrodes, which causes bad contact between the electrode and the active layer, as well as diffusion of the active layer components such as P3HT:PCBM into the CNT film. ${ }^{[38,132]}$ A common approach to address this problem is the embedding of CNTs films in conducting polymers, which will be discussed in detail in the section Composite Materials.

Furthermore, carbon nanotube - graphene hybrid electrodes have also been studied. Tung et al. ${ }^{[137]}$, for instance, fabricated transparent hybrid films from CNTs and chemically converted graphene by solution processing, which showed a resistance of $240 \mathrm{Ohm} \mathrm{sq}^{-1}$ at $86 \%$ transmittance $(\mathrm{FoM}=10)$. Films made from SWCNT and CVD deposited graphene displayed a similar sheet resistance of $300 \mathrm{Ohm} \mathrm{sq}^{-1}$, but a much higher transmittance of $96 \%$, resulting in a FoM of $30 .{ }^{[138]}$ Similar hybrid films made of MWCNT and CVD graphene were studied by Kholmanov et al. ${ }^{[139]}$, who showed that the opto-electronic properties of the hybrid electrodes depended strongly on the processing protocol, such as the order in which the graphene and CNT 
layers are deposited. The integration of a SWCNT - graphene oxide hybrid system in an OPV device with a P3HT/PCBM active layer was reported by Tu et al. ${ }^{[140]}$. This OPV device, comprising a SWCNT electrode and separate hole transporting interfacial layer of graphene oxide, showed power conversion efficiency of $3.1 \%$.

In summary it can be stated, that, despite the extremely high conductivity of CNTs and graphene, the opto-electronic properties of thin graphene and CNT films cannot compete with those of metal or metal oxide based transparent electrodes, which can be attributed to structural defects and high junction resistances. In addition, the solution processing of graphene and CNT was proven to be difficult, owing to the poor dispersability of the chemically inert carbon structure. Furthermore, the obtained graphene and CNT films show a high surface roughness, which is detrimental for the integration in devices.

\subsection{Conducting polymers}

Among polymers, traditionally known as good insulating materials, (semi)conducting polymers have attracted a great deal of attention as new class of materials and have been extensively studied since their discovery in the 1970s. The conductivity in conducting polymers is based on a conjugated $\pi$-electron system, which enables charge transport via delocalized electrons along the polymer backbone. Therefore the electronic properties depend strongly on the chemical structure of the polymer backbone. Even if the first polymer, in which conductivity was observed, is the linear polyacetylene, most conducting polymers are aromatic, such as polyaniline (PANI), Polypyrrole (PPy), poly (para-phenylene) (PPP) and polythiophene (PT) and their substituted derivatives. 
The electronic structure of these $\pi$-conjugated polymers can be described by a band structure, in which the energetically lower $\pi$ band is completely filled, whereas the energetically higher energy band $\pi^{*}$ is empty. Therefore most conducting polymers are actually semiconductors. Via doping of the polymer, for instance by oxidation, electronic states are generated in the band gap. At low oxidation (doping) levels radical cations, so called polarons, are formed on the polymer chain and represent localized states in the band diagram. Upon further oxidation spin-less dications, called bipolarons, are created, which form, with increasing doping, bipolaronic bands in the energy gap (see Figure 15). This doping process does not only render the polymer conducting, but also affects its optical properties, which become dominated by sub-band gap transitions. For the doping of a semiconducting polymer several processes can be used, including photochemical, interfacial or electrochemical reactions. The big advantages of conducting polymers compared to other classes of conducting materials are their chemical and mechanical stability, their flexibility, bio-compatibility, and the possibility to process them on a large scale at ambient temperatures.

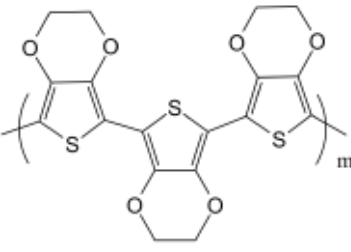

PEDOT neutral

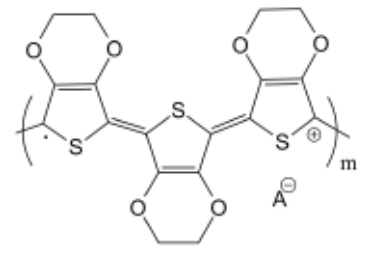

PEDOT polaron

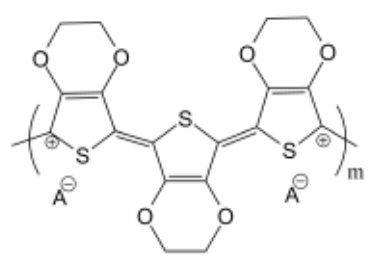

PEDOT

bipolaron

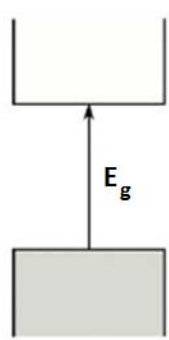

Neutral Polymer

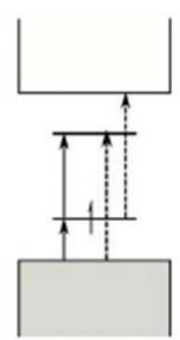

Polaron States

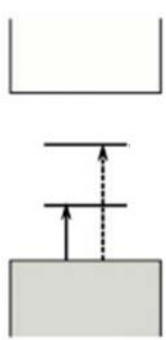

Bipolaron States

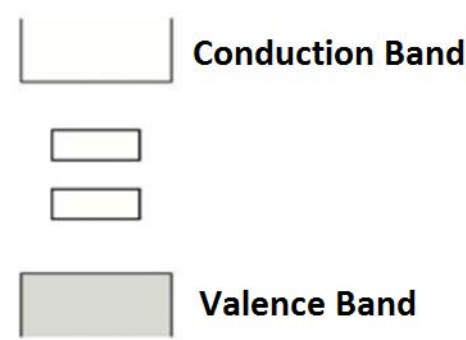

Bipolaron Bands 
Figure 15 Chemical structure of neutral, simple and double oxidized poly(3,4ethylenedioxythiophene) (PEDOT) and schematic of the corresponding band diagram

One of the most studied conducting polymers is PANI, which exist in several oxidation and protonation states (see Figure 16), of which the most stable and conducting form is the emeraldine salt. ${ }^{[141]}$ The conducting PANI is soluble in common organic solvents and absorbs in the range of $300 \mathrm{~nm}$ to $500 \mathrm{~nm}$, which gives it a greenish color. Thin PANI films can be obtained by either chemical oxidation of aniline in acidic aqueous medium or by electropolymerization and typically show a conductivity in the range of $5 \mathrm{~S} \mathrm{~cm}^{-1}$ to $20 \mathrm{~S} \mathrm{~cm}^{-1}$. ${ }^{[41-144]}$ Especially in the early stages of the research on conducting polymers several attempts were made to fabricate PANI transparent electrodes. ${ }^{[41,145-147]}$ Heeger and coworkers ${ }^{[145]}$ fabricated thin PANI films with $100 \mathrm{Ohm} \mathrm{sq}^{-1}$ at $70 \%$ transmittance at $475 \mathrm{~nm}$ to $675 \mathrm{~nm}(\mathrm{FoM}=10)$. A simple flexible OLED device (PANI/MEH-PPV/Ca) with similar PANI electrodes showed a quantum efficiency of $1 \%$ and a turn on voltage of $1.8 \mathrm{~V} \cdot{ }^{[146]}$ The main limiting factor for the performance of these devices was the low transmittance of the electrodes. ${ }^{[147]}$ In addition, the work function of PANI was reported to be $4.4 \mathrm{eV}^{[145]}$, which is very low compared to commonly used active layer materials and results therefore in a high energy barrier and a high series resistance in the devices. 


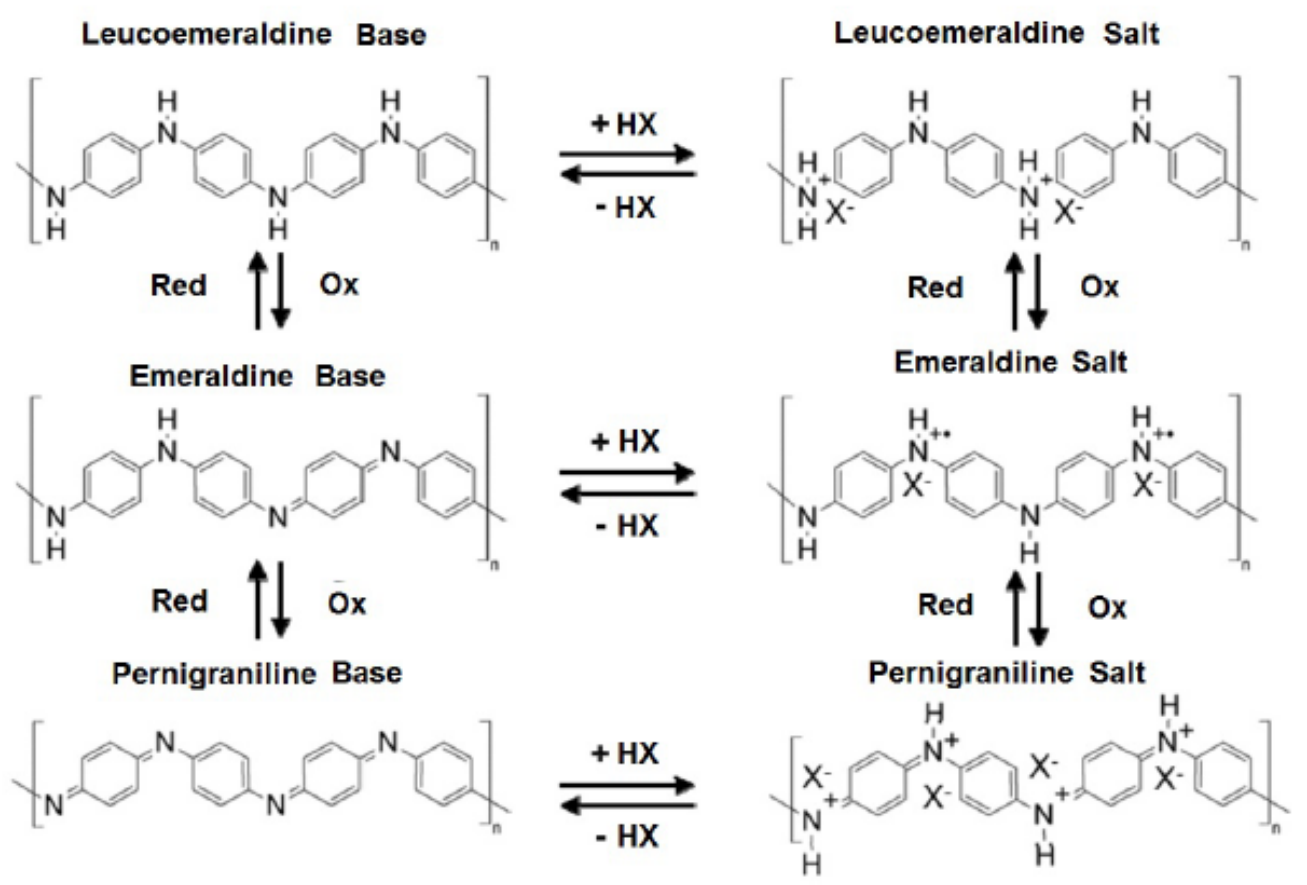

Figure 16 Different oxidation and protonation states of polyaniline (PANI)

A more promising alternative to PANI for transparent electrodes is the substituted thiophene poly(3,4-ethylenedioxythiophene) (PEDOT) (see Figure 15), which is highly conducting and sky blue in the doped state. Doping of PEDOT is obtained by partial oxidation of the thiophene units and it has been shown that the doping is optimized for $33 \%$ to $36 \%$ charged repeating units. $^{[148-151]}$ To counter balance the positive charges on PEDOT, anionic counter ions are integrated in the PEDOT structure. Depending on the nature and size of these counter ions, the structure and doping of the obtained PEDOT system can be affected. ${ }^{[152,153]}$ The work function of PEDOT materials is reported to be between $4.8 \mathrm{eV}$ and $5.2 \mathrm{eV}^{[11,154-156]}$, which is close to the work function of ITO $(4.8 \mathrm{eV})$ and allows the use of PEDOT films as anode in organic electronic devices.

There are three main methods which allow the fabrication of conducting PEDOT films.

One possibility is the electro-polymerization of PEDOT films onto a conducting substrate. This process allows a good control of the oxidation level and the incorporation of different small or polymeric counter ions and results in transparent films with a conductivity from $50 \mathrm{~S} \mathrm{~cm}^{-1}$ to 
$700 \mathrm{~S} \mathrm{~cm}^{-1} \cdot{ }^{[152,157-162]}$ However, electro-polymerization is not possible on insulating substrates, such as poly(ethylene terephthalate) (PET), and is not compatible with the large scale printing of organic electronic devices.

An alternative process is the oxidative polymerization of EDOT, which has been described in innumerable protocols, using different oxidants, counter ions, catalysts, temperatures and synthesis times. ${ }^{[149,150,163-171]}$

One possibility is the in-situ oxidative polymerization of EDOT in liquid phase, for which the PEDOT film is directly polymerized from a solution containing the EDOT monomer and the oxidizing agents, such as $\mathrm{FeCl}_{3}$, onto the substrate. By using a solution of $\mathrm{EDOT}$ and $\mathrm{FeCl}_{3}$ in acetonitrile, Hohnholz et al. ${ }^{[172]}$ obtained PEDOT:Cl films with a sheet resistance of $945 \mathrm{Ohm}$ $\mathrm{sq}^{-1}$. However, it was shown that the conductivity can be significantly increased by choosing $\mathrm{Fe}(\mathrm{III}) \mathrm{p}$-toluenesulfonate $\left(\mathrm{Fe}(\mathrm{Tos})_{3}\right)$ as oxidant, a low molecular weight alcohol, such as butanol, as solvent and by the addition of a weak base, such as imidazole or pyridine, which slows down the reaction kinetics. ${ }^{[171,173-176]}$ From a solution of EDOT, Fe(Tos) 3 and imidazole in methanol Ha et al. ${ }^{[171]}$ fabricated thin PEDOT:Tos films with a sheet resistance of $150 \mathrm{Ohm}$ $\mathrm{sq}^{-1}$ at a transmittance higher than $80 \%(\mathrm{FoM}=11)$ and a conductivity of $900 \mathrm{~S} \mathrm{~cm}^{-1}$. More recently Bubnova et $a .^{[175]}$ reported an even higher conductivity of semi-crystalline PEDOT:Tos films of $1500 \mathrm{~S} \mathrm{~cm}^{-1}$.

The same reaction, which is used for the liquid in-situ polymerization of EDOT, can also be performed in the vapor phase. For this process a substrate coated with a mixture of the oxidant, e.g. $\mathrm{Fe}(\mathrm{Tos})_{3}$, and a base, such as pyridine, is exposed to EDOT vapors under ambient conditions or in vacuum ${ }^{[177]}$, which results in the slow formation of a PEDOT:anion film on the substrate. In this way PEDOT:Tos films with extremely high conductivities of up to $3400 \mathrm{~S} \mathrm{~cm}^{-}$ ${ }^{1}$ can be obtained, which show opto-electronic properties $\left(R_{s}=45 \mathrm{Ohm} \mathrm{sq}^{-1}\right.$ at $\mathrm{T}>80 \%$, FoM=35) that meet the requirements for transparent electrode applications. ${ }^{[178]}$ The integration of less conducting vapor polymerized PEDOT:Tos films, for instance with $R_{s}=215 \mathrm{Ohm} \mathrm{sq}^{-1}$ 
at $\mathrm{T}>84 \%$, in OPV devices resulted in comparable device performance as the benchmark devices. ${ }^{[179,180]}$ An analogous route was presented by Gleason and co-workers ${ }^{[149]}$, who obtained $100 \mathrm{~nm}$ thick PEDOT films with a conductivity of $105 \mathrm{~S} \mathrm{~cm}^{-1}$ at $84 \%$ transmittance by exposing a substrate coated with EDOT monomer to oxidants and pyridine vapors. However, the synthesis of PEDOT from vapor phase is time consuming and not straight forward to set up. For the sake of simple processing, aqueous PEDOT dispersions have been developed, which make it possible to fabricate PEDOT thin films by various coating techniques, such as spin coating, roll-to-roll coating or printing. In order to stabilize the insoluble PEDOT in aqueous medium, the EDOT is polymerized in the presence of an anionic polyelectrolyte, which acts in the same time as counter ion, template and stabilizer for the doped PEDOT. The polyanion commonly used for this purpose is poly(styrene sulfonate) (PSS), which is the polymeric homolog of p-toluene sulfonate (Tos) and which is transparent in the visible range. The resulting PEDOT:PSS dispersions show excellent film-forming properties, flexibility, thermal stability up to about $200{ }^{\circ} \mathrm{C}$ and an adequate transparency in the visible range. Upon drying of the PEDOT:PSS films PEDOT rich domains are formed, which are embedded in a PSS rich phase ${ }^{[181]}$. This insulating PSS phase represents an energy barrier for the charge transport in the film. Therefore PEDOT:PSS shows a much lower conductivity than PEDOT:Tos of only about $0.1 \mathrm{~S} \mathrm{~cm}^{-1}$ to $10 \mathrm{~S} \mathrm{~cm}^{-1} \cdot{ }^{[167,182,183]}$ As this conductivity is far too low for an efficient application of PEDOT:PSS as transparent electrode in opto-electronic devices, a huge effort has been made to improve the conductivity of PEDOT:PSS by formulation and post-treatments. It is well established that the conductivity of PEDOT:PSS can be enhanced for more than three orders of magnitude via formulation or post-treatment with high boiling point solvents, such as ethylene glycol (EG), diethylene glycol (DEG), dimethylsulfoxide (DMSO), N,Ndimethylformamide (DMF) or sorbitol. ${ }^{[156,175,182,184-192]}$ PEDOT:PSS films, fabricated with different co-solvents showing conductivities of $300 \mathrm{~S} \mathrm{~cm}^{-1}$ to $600 \mathrm{~S} \mathrm{~cm}^{-1}$ (e.g. $80 \mathrm{Ohm} \mathrm{sq}^{-1}$ at $74 \%$ transmittance, FoM=15), were successfully integrated as transparent electrode in flexible 
OPV devices. The devices showed an efficiency of about $3 \%$, which was comparable to the efficiency of the ITO reference devices ${ }^{[193-195]}$ and the efficiency was stable over 300 bending cycles. ${ }^{[193]}$ Ouyang et al. ${ }^{[184]}$ reported the integration of EG treated PEDOT:PSS electrodes ( $\sigma$ $=160 \mathrm{~S} \mathrm{~cm}^{-1}$ ) in OLEDs, which displayed a power efficiency of $1.5 \%$ and similar characteristics as the ITO reference device.

The underlying mechanism, which leads to the increase in conductivity, has been widely discussed, but is yet not fully understood. However, it was shown that the oxidation state of PEDOT was not affected and that the change in conductivity is related to morphological changes on the nanometric and micrometric scale. A widely supported explanation is, that the presence of a high boiling point solvent induces a phase segregation of the PEDOT rich and the PSS rich phase, which leads to the growth of the PEDOT rich domains ${ }^{[191,196]}$, better percolation ${ }^{[152,175,182,188,190,191]}$ and the reduction of the PSS rich surface layer ${ }^{[182,188,192,197]}$. In addition, the co-solvents can act as plasticizer, which incites the re-arrangement and better packing of the PEDOT chains. ${ }^{[156,186,197-201]}$

Furthermore, it was reported that the treatment of PEDOT:PSS with certain salts, zwitterions and ionic liquids can induce a similar increase in the film conductivity. ${ }^{[202-208]}$ This was explained by the charge screening effect of the ions, which weakens the PEDOT - PSS interactions and allows a rearrangement of the polymer chains. ${ }^{[203-205]}$ By using a treatment with methylammonium iodide in DMF Ouyang and co-workers ${ }^{[207]}$ obtained PEDOT:PSS films with a conductivity of up to $2200 \mathrm{~S} \mathrm{~cm}^{-1}$. The integration of such films into OPV devices revealed, that similar characteristics and performance can be obtained with highly conducting PEDOT:PSS electrodes as for ITO electrodes. Very similar results were presented by Badre et al. ${ }^{[208]}$, who obtained PEDOT:PSS films with a sheet resistance of $31 \mathrm{Ohm} \mathrm{sq}^{-1}$ at $\mathrm{T}>96 \%(\sigma$ $\left.=2084 \mathrm{~S} \mathrm{~cm}^{-1}, \mathrm{FoM}=295\right)$, upon formulation of PEDOT:PSS with the ionic liquid 1-ethyl-3methylimidazolium tetracyanoborate. However, potential residual ions which remain in the 
films will move through the film under the application of an electric field, which could influence the device performance.

Another approach to enhance the conductivity of PEDOT:PSS is the post coating treatment of PEDOT:PSS films with strong acids. ${ }^{[202,209-211]}$ Upon repeated rinsing with sulfuric acid PEDOT:PSS films with conductivities of higher than $3000 \mathrm{~S} \mathrm{~cm}^{-1}$ were obtained, which displayed metallic conduction behavior at room temperature. ${ }^{[202]}$ OPV devices fabricated with $\mathrm{H}_{2} \mathrm{SO}_{4}$ treated PEDOT:PSS electrodes of $109 \mathrm{~nm}$ thickness with $R_{S}=39 \mathrm{Ohm} \mathrm{sq}^{-1}$ and T $>80 \%$ $(\mathrm{FoM}=41)$, displayed comparable characteristics and efficiencies as ITO reference devices. ${ }^{[202]}$ However, the treatment with strong acids is not adapted to large scale processing, owing to the corrosivity of the acids, which can damage other materials involved in the process and raises safety issues during processing.

More recently it has been demonstrated that other anionic polyelectrolytes than PSS can be used to successfully dope and disperse PEDOT in water ${ }^{[153,212]}$. This opens up possibilities for the design of new conducting PEDOT systems with tailored properties for specific applications. The use of a polyanion bearing bis(sulfonyl)imide groups, for example, allowed the fabrication of conducting electrodes with an extremely high transparency, much higher then PEDOT:PSS, and an intermediate conductivity of $220 \mathrm{~S} \mathrm{~cm}^{-1} \cdot{ }^{[212]}$ OLED devices based on such electrodes $\left(\mathrm{FoM}=16, R_{s}=100 \mathrm{Ohm} \mathrm{sq}^{-1}\right.$ at $T=80 \%$ and $R_{s}=200 \mathrm{Ohm} \mathrm{sq}^{-1}$ at $T=90 \%$ ) displayed slightly higher efficiencies than the PEDOT:PSS reference devices. ${ }^{[212]}$

In conclusion, it can be stated, that the only state of the art conducting polymer which displays suitable conductivities to serve as transparent electrode is PEDOT. Transparent conducting films based on PEDOT show good opto-electronic properties with conductivities of up to 3000 $\mathrm{S} \mathrm{cm}{ }^{-1}$ and high transparency, which are comparable to the characteristics of metal based transparent electrodes. In addition, the aqueous dispersion PEDOT:PSS allows the solution processing of PEDOT into thin, conducting, smooth and flexible films, which display 
comparable performance in devices as ITO reference electrodes. However, the use of PEDOT:PSS in devices was shown to accelerate device degradation, due to its hygroscopic and corrosive nature. $^{[213-215]}$

\section{Composite Materials}

\subsection{Metal - metal oxide composites}

As discussed earlier, thin films of metal oxides can display high conductivities of up to $10^{4} \mathrm{~S}$ $\mathrm{cm}^{-1}$ combined with high transparency in the visible range and are currently used as state of the art transparent electrodes. However, it still is of interest to decrease the sheet resistance of the transparent electrodes to further improve the device performance. One approach consists in combining metal oxides with metals, which show conductivities that are about one order of magnitude higher than the conductivities of the most performant metal oxides. A multi-layer electrode made of ITO/Ag/ITO, presented by Guillen et al. ${ }^{[216]}$, displayed a sheet resistance of $6 \mathrm{Ohm} \mathrm{sq}^{-1}$ and a transmittance of higher than $90 \%(\mathrm{FoM}=580)$. Jeong and Kim demonstrated, that the opto-electronic properties of such ITO/Ag/ITO sandwich structures strongly depend on the thickness of the Ag interlayer and that organic solar cells comprising an optimized ITO/Ag/ITO electrode $\left(R_{s}=4.4 \mathrm{Ohm} \mathrm{sq}^{-1}\right)$ outperformed the ITO reference device. ${ }^{[217]}$ Also indium free multilayer electrodes, based on $\mathrm{ZnO}^{[218]}$ or $\mathrm{SnO}^{[219]}$ and $\mathrm{Ag}$, were reported to show excellent performance with sheet resistances as low as $3 \mathrm{Ohm} \mathrm{sq}^{-1}$ at $90 \%$ transmittance $(\mathrm{FoM} \approx 1100) .{ }^{[218]}$ However, these multilayer systems do not address the demand for low cost electrodes for large scale, flexible devices.

Another promising type of metal-metal oxide composites are Ag nanowire networks coated with $\mathrm{ZnO}^{[220]}, \mathrm{ZnO}$ nanoparticles ${ }^{[221]}, \mathrm{SnO}_{\mathrm{x}}{ }^{[222]}$ or ITO nano-particles ${ }^{[223]}$. Due to the metal oxide coating the conductivity as well as the mechanical and thermal stability of the nanowire films were enhanced and the surface roughness was reduced. In this way, indium free and all 
solution processed $\mathrm{Ag} / \mathrm{ZnO}^{[220]}$ and $\mathrm{Ag} / \mathrm{SnO}_{\mathrm{x}}{ }^{[222]}$ films with sheet resistances of $11 \mathrm{Ohm} \mathrm{sq}^{-1}$ and $5 \mathrm{Ohm} \mathrm{sq}^{-1}$ at $93 \%$ and $87 \%$ transmittance $(\mathrm{FoM} \approx 450)$, respectively, were obtained.

\subsection{Metal - polymer composites}

A very promising approach for high performance transparent electrodes are composite materials of metal nano-structures and conducting polymers, as they combine the high conductivity of the nano-structures and the high transparency, flexibility and smooth surface of polymer films. The fabrication process of metal nanowire - polymer composites commonly includes several steps. One possible fabrication method is the deposition of the metal nanowire film in the first step and the subsequent over-coating of the metal network with the transparent polymer. ${ }^{\text {[224-226] }}$ Another possibility is the separate preparation of the two films, which are then laminated onto each other. ${ }^{[227-230]}$ As metal nanowire films show a very high conductivity, any transparent and flexible polymer can be used in the composite film to assure the mechanical stability of the electrode. Therefore several combinations of silver nanowire films with different polymers, such as polyimides ${ }^{[224]}$, polymethacrylate ${ }^{[225]}$, polyvinylacetate $(\mathrm{PVAc})^{[226]}$ and polyurethane urea (PUU) - polydimethylsiloxane (PDMS) ${ }^{[230]}$ have been studied. With these systems, typical sheet resistances of $8 \mathrm{Ohm} \mathrm{sq}^{-1}$ to $10 \mathrm{Ohm} \mathrm{sq}^{-1}$ at $80 \%$ transmittance (FoM 160 to 200) have been achieved. ${ }^{[224,225,230]}$ By varying the density of the nanowire network it is possible to play on the transparency and conductivity of the films (see Figure 17). ${ }^{[230]}$ 

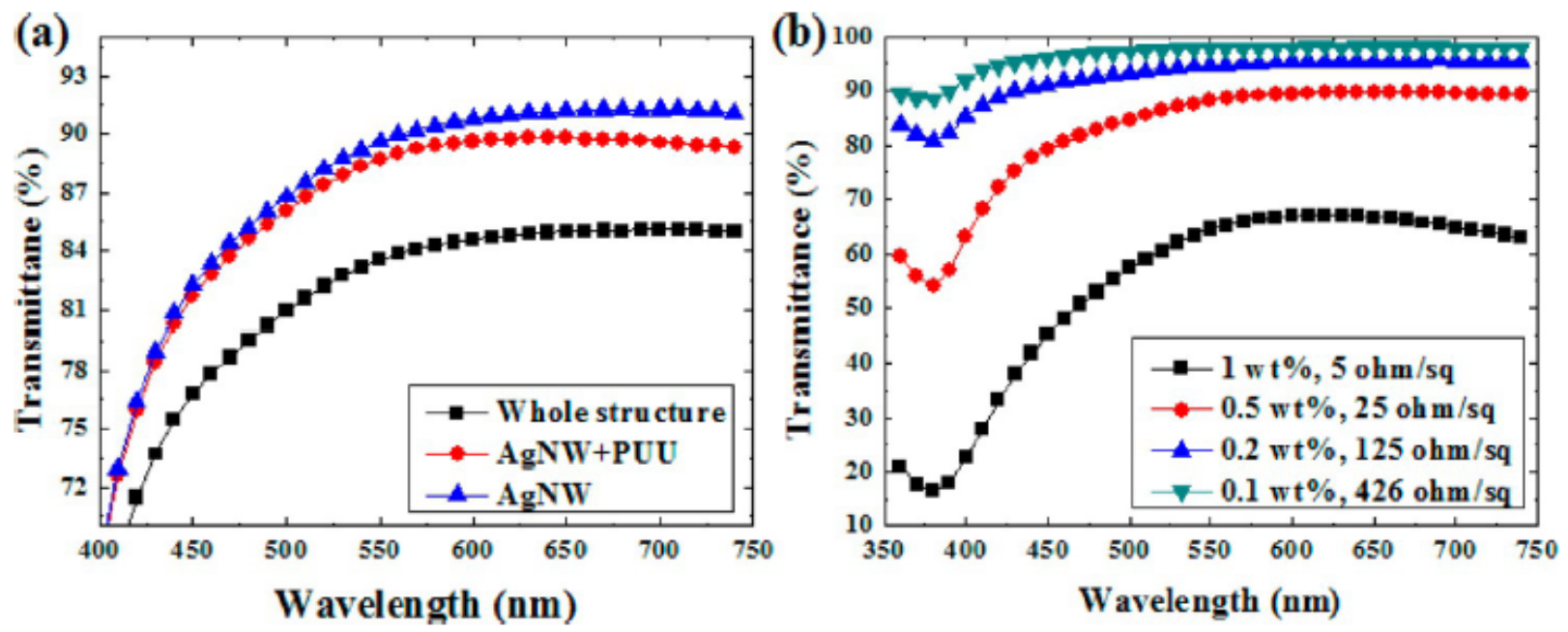

Figure 17 Transmittance of the AgNW/PUU/PDMS film: (a) comparison of transmittance for AgNW/PUU/PDMS, AgNW/PUU, and AgNW layers $\left(R_{s}=30 \mathrm{Ohm} \mathrm{sq}^{-1}\right)$ and $(\mathrm{b})$ effect of nanowire density on transmittance of AgNW layer. ${ }^{[230]}$ (Reproduced with permission. 2015, American Chemical Society)

In order to reduce the cost of the integrated nanowires, the use of the more abundant $\mathrm{Cu}$ is of interest. Promising results for the replacement of $\mathrm{Ag}$ by $\mathrm{Cu}$ nanowires were presented by Song et $a .^{[228]}$, who reported PDMS - $\mathrm{Cu}$ nanowire based composite electrodes with a sheet resistances of $62 \mathrm{Ohm} \mathrm{sq}^{-1}$ and $80 \%$ transmittance $(\mathrm{FoM}=26)$, which were integrated in highly flexible and stretchable OLED devices $\left(35 \mathrm{~lm} \mathrm{~W}^{-1}, 57 \mathrm{Cd} \mathrm{A}^{-1}, 10 \mathrm{~mA} \mathrm{~m} \mathrm{~m}^{-2}\right)$. For all metal nanowire composites, in which insulating polymers are used as matrix material, it is crucial, that the metal structure is exposed to the surface of the electrode, in order to ensure good electric contact with the active layer in devices. This can either be assured by choosing an appropriate fabrication process or by the post-treatment of the film by plasma etching, which removes polymer on the film surface. ${ }^{[22]}$ Therefore, the use of insulating polymers as support for metal nanowires films enhances the mechanical stability of the films, but does not drastically decrease the surface roughness. However, by using a conducting polymer, such as PEDOT:PSS, as matrix material, the metal nano-structure can be fully embedded in a smooth film. In addition, 
PEDOT:PSS can provide electrical contact at the nanowires junctions, which allows to omit the thermal annealing step that is commonly used to improve the electrical contact between the single Ag wires. ${ }^{[231]}$ McGehee and co-workers presented PEDOT:PSS - Ag nanowire composite electrodes, which were obtained by lamination of a Ag network on PEDOT:PSS with different film thicknesses (see Figure 18). ${ }^{[227]}$ These electrodes showed a very good opto-electronic performance with $R_{s}=12 \mathrm{Ohm} \mathrm{sq}^{-1}$ at $86 \%$ transmittance (FoM=200) and good flexibility. By over-coating of a Ag nanowire network with PEDOT:PSS, composite electrodes with $\mathrm{R}_{\mathrm{s}}=14$ $\mathrm{Ohm} \mathrm{sq}^{-1}$ to $25 \mathrm{Ohm} \mathrm{sq}^{-1}$ and $\mathrm{T}>80 \%$ were obtained ${ }^{[231,232]}$, which were successfully integrated in an A4-size touch screen panel ${ }^{[231]}$ and OPV devices with an efficiency of $3.1 \%$ (ITO reference: $3.5 \%) .{ }^{[232]}$ Similar results were obtained for hydrothermally synthesized $\mathrm{Cu}$ nanowires embedded in PEDOT:PSS, which displayed a sheet resistance of $46 \mathrm{Ohm} \mathrm{sq}^{-1}$ at $93 \%$ transmittance, FoM=111. ${ }^{[233]}$ Apart from nanowire networks also metal nano-grids were successfully combined with PEDOT:PSS films. Kang et al. ${ }^{[234]}$, for instance, fabricated a transparent composite electrode with $R_{S}=22 \mathrm{Ohm} \mathrm{sq}^{-1}$ at $78 \%$ transmittance $(\mathrm{FoM}=65)$ by rollto-roll processing of a nano-imprinted $\mathrm{Cu}$ mesh on a PEDOT:PSS film, which showed comparable performance to ITO electrodes in OPV devices.
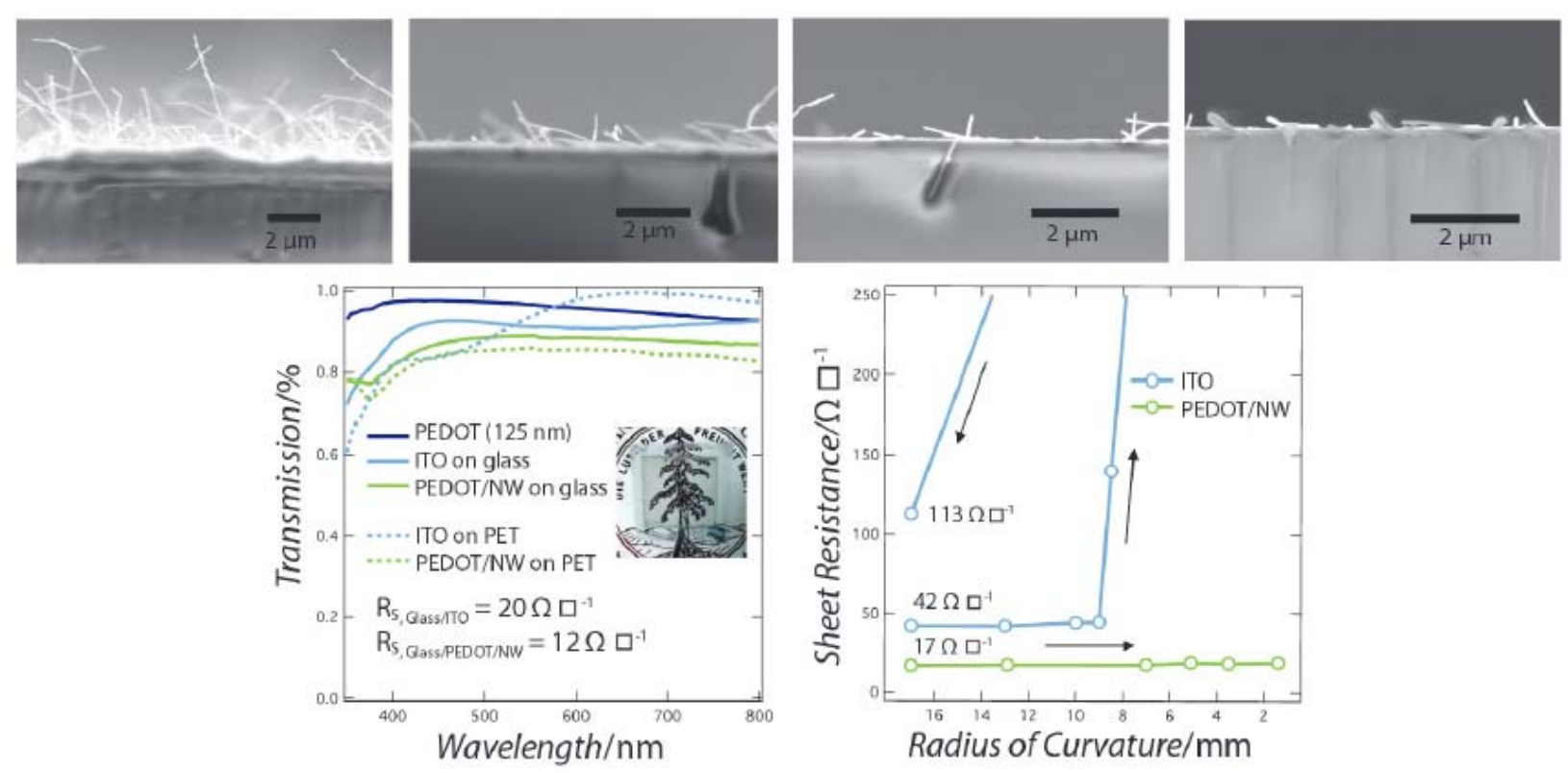
Figure 18 SEM images of a Ag nanowire network laminated on PEDOT:PSS films of different thickness (top), transmission in the visible spectrum of ITO, PEDOT:PSS and Ag nanowirePEDOT:PSS films and sheet resistance of an ITO and a Ag nanowire-PEDOT:PSS film as a function of bending radius. ${ }^{[227]}$ (Reproduced with permission. 2011, John Wiley and Sons)

An approach, which combines lithography, electrodeposition and imprint transfer, was recently presented by Khan et al. ${ }^{[235]}$. The obtained electrodes, composed of a $\mathrm{Cu}$ grid embedded in a cyclic olefin copolymer matrix, were flexible and displayed an extremely low sheet resistance of less than $1 \mathrm{Ohm} \mathrm{sq}^{-1}$ at more than $70 \%$ transmittance $(\mathrm{FoM}>1500)$ with a surface roughness lower than $50 \mathrm{~nm}$.

It has to be taken into account, that transparent nanostructured metal electrodes are almost always coated with PEDOT:PSS upon integration into devices, as PEDOT:PSS is used as standard hole transport layer. In addition, it smoothens the surface of the metal film, which reduces the leakage current. ${ }^{[226]}$ Therefore almost all electrodes presented in literature as metal nanowire/nanogrid electrodes can be actually seen as metal - conducting polymer composite systems. ${ }^{[102]}$

\subsection{Carbon Nanotube - polymer composites}

Another extensively studied composite material are carbon nanotube (CNT) - conducting polymer composites. In these systems the CNTs represent the highly conducting component, whereas the polymer accounts for the processability, transparency and flexibility of the material. The main resistance of the macroscopic CNT films is caused by the junctions between the CNTs, which represent an energy barrier to the charge transport. Therefore the electronic properties of such CNT - polymer composites are strongly dependent on the concentration of the CNTs in 
the polymer matrix, which can be explained by the percolation theory. ${ }^{[121]}$ At low CNT concentrations there are no continuous highly conducting paths through the film and the conductivity is dominated by the electrical properties of the polymer matrix. At a critical CNT concentration, called the percolation threshold, a continuous network of the highly conducting CNTs is formed and therefore the electrical conductivity of the composite jumps up. For higher CNT concentrations the conductivity saturates, as multiple conducting paths have already been formed. By using nano-structures with high aspect ratios the percolation threshold can be lowered, which is beneficial for the fabrication of highly transparent films.

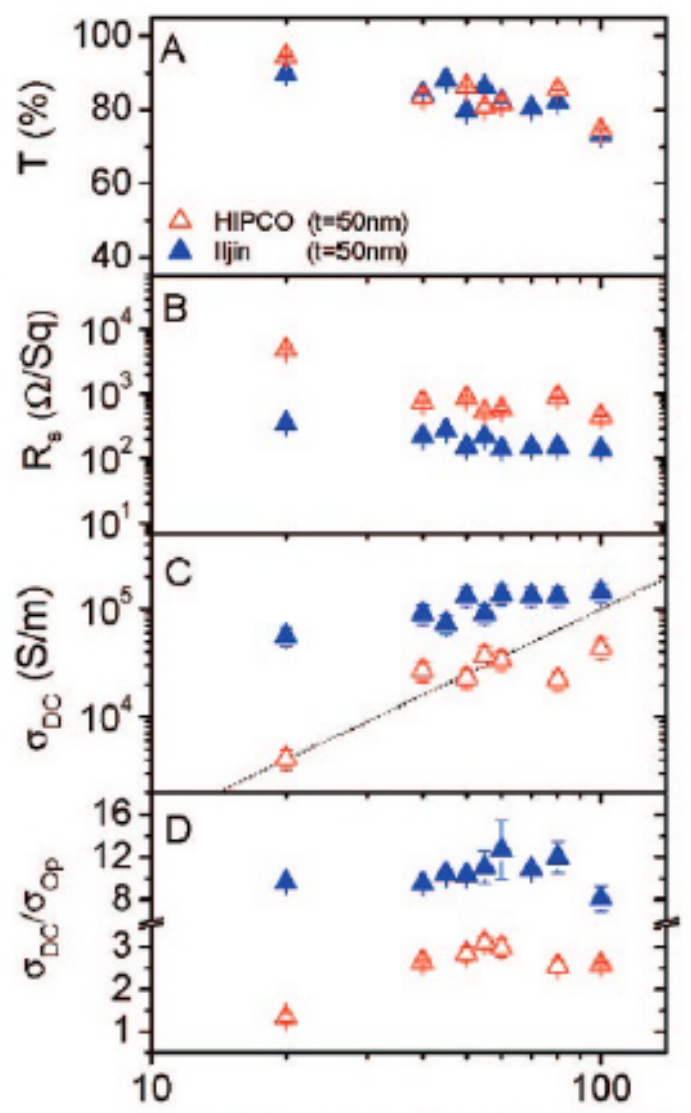

Nanotube mass fraction, $\mathrm{M}_{\mathrm{f}}(\%)$

Figure 19 Opto-electronic properties of HIPCO SWCNT (red triangles) and Iljin SWCNT (blue triangles) SWCNT-PEDOT:PSS composite films as a function of the SWCNT mass fraction. ${ }^{[236]}$ (Reproduced with permission. 2009, American Chemical Society) 
A straight forward approach to the fabrication of CNT-polymer composite films is the mixing of the two components in dispersion, which allows the film fabrication in one coating step. By using this approach flexible SWCNT-PEDOT:PSS electrodes with typical sheet resistances of $80 \mathrm{Ohm} \mathrm{sq}^{-1}$ to $130 \mathrm{Ohm} \mathrm{sq}^{-1}$ at $75 \%$ transmittance $(\mathrm{FoM}=15)$ were obtained. ${ }^{[236-240]}$ De et al. ${ }^{[236]}$ reported that the opto-electronic performance was maximized for a SWCNT content of $60 \%$, at which the composite film even outperformed the pure SWCNT in terms of the FoM (see Erreur! Source du renvoi introuvable.). SWCNT-PEDOT:PSS electrodes fabricated by layer-by-layer coating of SWCNT and pristine PEDOT:PSS displayed a very similar performance ${ }^{[132,239]}$. An important parameter, which must be considered for the fabrication of CNT-PEDOT:PSS electrodes, is the quality of the CNT dispersion, as it strongly affects the opto-electronic performance of the composite material. ${ }^{[239]}$

In OPV devices SWCNT-PEDOT:PSS composite electrodes clearly outperformed the SWCNT electrodes, despite the higher sheet resistance of the composite films, ${ }^{[132]}$ which was explained by a smoother interface between the electrode and the active layer. Flexible OLEDs comprising SWCNT-PEDOT:PSS electrode showed a higher luminance than the ITO reference device for low driving voltages $<15 \mathrm{~V}$, which can be related to the higher work function of PEDOT:PSS compared to ITO. At higher driving voltage the composite device displayed lower luminance than the ITO device, owing to the higher sheet resistance of the SWCNT-PEDOT:PSS electrode. $[238]$

Jo et al. ${ }^{[240]}$ reported that the sheet resistance of a SWCNT film was significantly decreased from $1250 \mathrm{Ohm} \mathrm{sq}^{-1}$ to $280 \mathrm{Ohm} \mathrm{sq}^{-1}$ upon vapor deposition of PEDOT:Tos on the SWCNT network. The beneficial effect of PEDOT:Tos on the film conductivity was explained by the formation of conducting PEDOT:Tos bridges between the SWCNTs. Via these bridges, the charge transfer from CNT to PEDOT to CNT allowed effective percolation, leading to a reduction of the sheet resistance (see Erreur ! Source du renvoi introuvable.). 


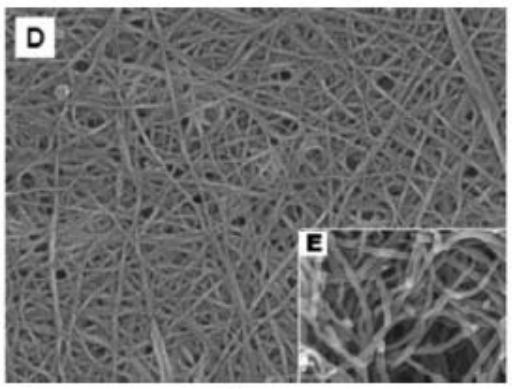

Sample

SWCNT (1) only

SWCNT (2) only

SWCNT (1):PEDOT (1:0.8) hybrid

SWCNT (2):PEDOT (1:0.8) hybrid

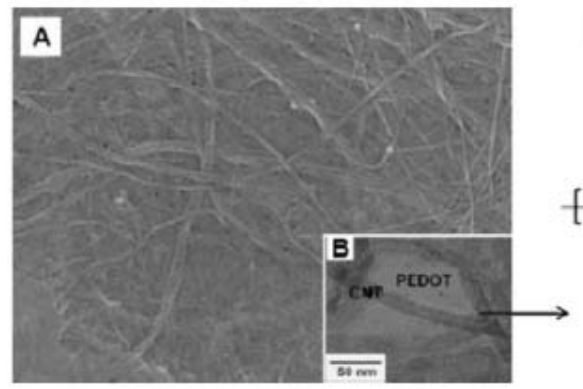

C

Conductivity; Sheet resistance at $85 \%$ $\sigma(\mathrm{S} / \mathrm{cm}) \quad$ transmittance; $R_{\mathrm{s}}(\Omega / \mathrm{sq}$. )

$800 \quad 1250$

$285 \quad 3500$

$2900 \quad 350$

$1200 \quad 700$

Figure 20 a) SEM image, b) TEM image and c) schematic structure of a SWCNT-PEDOT:Tos composite film and d) SEM image, e) TEM image of pure SWCNT film and comparison of the opto-electronic properties of both systems (bottom). ${ }^{[240]}$ (Reproduced with permission. 2012, Elsevier)

More recently Cho et al. ${ }^{[241]}$ presented a more complex composite system, composed of MWCNT, gold and PEDOT:PSS, which showed a far better opto-electronic performance than the approaches presented above, with a sheet resistance of $51 \mathrm{Ohm} \mathrm{sq}^{-1}$ at $86 \%$ transmittance, resulting in a FoM of 47. For the fabrication of these electrodes, gold nano-particles (AuNP) were synthesized on MWCNT using a polyol process. The AuNP covered MWCNT were subsequently dispersed in PEDOT:PSS containing $5 \%$ DMSO. After the film deposition by spin coating the films were treated with plasma irradiation leading to the fusion of the AuNP, which formed conducting bridges between the MWCNTs (see Erreur! Source du renvoi introuvable.). 

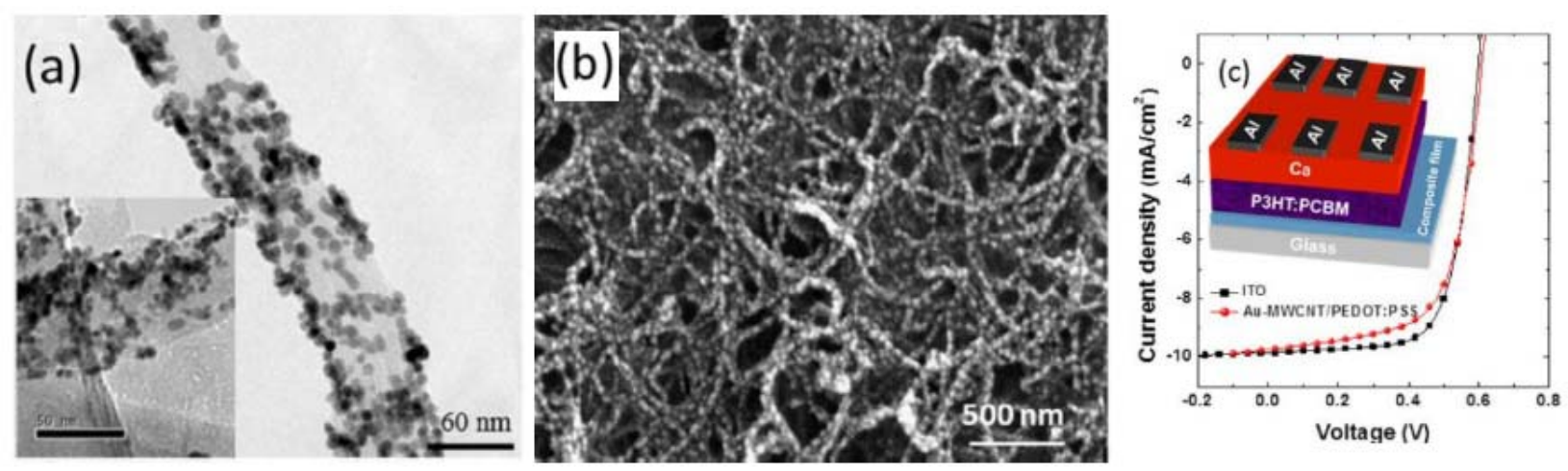

Figure 21 a) TEM image of AuNP covered MWCNT, b) SEM image of a AuNP - MWCNT film after plasma treatment and c) IV characteristics and schematic structure of OPV devices with MWCNT-Au-PEDOT:PSS or ITO electrode. ${ }^{[241]}$ (Reproduced with permission. 2015, American Chemical Society)

Apart from PEDOT, other conducting polymers have been investigated as matrix material for CNT composite electrodes. Both, Polyaniline (PANI) and polypyrrole (PPy), for instance, are cheap, flexible and show a high conductivity and are therefore interesting candidates for the fabrication of CNT-polymer composite electrodes. Ferrer-Anglada et al. ${ }^{[242]}$ fabricated transparent CNT-PANI and CNT-PPy electrodes by electro-polymerization of PANI or PPy on CNT films. Upon the deposition of the conducting polymer layer on the CNT network, the conductivity of the films increased from $3-20 \mathrm{~S} \mathrm{~cm}^{-1}$ to up to $60 \mathrm{~S} \mathrm{~cm}^{-1}$ for film transmittance between $75 \%$ and $90 \%$. Taking into account that the conductivity of the pure polymers is much poorer than the conductivity of the pure nanotubes, the increasing conductivity of the composite was attributed to a decreasing contact resistance between the nanotubes.

The conjugated polymer poly(3-hexylthiophene-2,5-diyl) (P3HT), well known as active layer component in organic solar cells, was found to disperse CNTs in chlorinated solvents. This allows the solution processing of thin, transparent conducting CNT-P3HT composite films, as it was shown by Hellstrom et al. ${ }^{[243]}$. After a post treatment with $\mathrm{SOCl}_{2}$, which dopes the CNTs and removes excess polymer, the composite films displayed a sheet resistance of $170 \mathrm{Ohm} \mathrm{sq}^{-}$ 
${ }^{1}$ at $81 \%$ transmittance $(\mathrm{FoM}=10)$ and of $80 \mathrm{Ohm} \mathrm{sq}^{-1}$ at $72 \%$ transmittance $(\mathrm{FoM}=13)$ for P3HT to CNT ratios of 15:1 and 5:1, respectively.

\section{Summary and Conclusion}

The above presented materials show promising characteristics for the application as transparent conducting electrode in organic devices. Nevertheless, a breakthrough material has not been found yet. Metal oxides display excellent opto-electronic properties, but their brittleness makes them unsuitable for the integration in flexible devices. Furthermore, the need for low cost solutions and simple processing with high quality is another limiting factor for the broad base application of metal oxides. Metallic nano-structures, such as metal grids or metal nano-wires, allow the fabrication of thin and flexible films with an extremely low sheet resistance and good transparency. However, their high surface roughness and mechanical fragility renders the application difficult. Similar problems are encountered for carbon nanotube and graphene films. In addition, their opto-electronic are poorer, despite the extremely high conductivity of the single carbon nano-structures, caused high junction resistances between the nano-structures. The big advantage of conducting polymer electrodes, mainly based on PEDOT, are their solution processability, extremely high flexibility and smooth surface roughness. For a long time their application was limited due to their insufficient opto-electronic properties. Recent developments, however, allow the fabrication of transparent polymer electrodes which can compete with CNT and metal nanowire electrodes in terms of the figure of merit. By combining metallic nano-structures with conducting polymers in hybrid films, the outstanding conductivity of the metal structure and the high transparency and mechanical stability of polymer result in thin films with excellent opto-electronic performance. 
Table 1 Qualitative comparison of the opto-electronic performance, advantages (indicated as

+ ) and drawbacks (indicated as -) of different transparent electrode materials

\begin{tabular}{|c|c|c|c|c|c|c|}
\hline $\begin{array}{c}\text { Material } \\
\text { Class }\end{array}$ & & $\begin{array}{c}\text { Typical } \\
\text { Range of } \\
\text { FoM }\end{array}$ & $\begin{array}{c}\text { Flexibility, } \\
\text { Mechanical } \\
\text { Stability }\end{array}$ & $\begin{array}{c}\text { Large Scale Processing/ } \\
\text { Printing }\end{array}$ & $\begin{array}{c}\text { Surface } \\
\text { Roughness }\end{array}$ & $\begin{array}{c}\text { Toxicity/ } \\
\text { Biocompatibility }\end{array}$ \\
\hline $\begin{array}{l}\text { Metal } \\
\text { Oxides }\end{array}$ & & $300-600$ & - & - & 0 & $-/ 0$ \\
\hline \multirow[t]{3}{*}{ Metals } & $\begin{array}{l}\text { Ultra-thin } \\
\text { films }\end{array}$ & 200 & - & - & 0 & + \\
\hline & Nanogrids & $200-700$ & 0 & 0 & - & + \\
\hline & Nanowires & $\begin{array}{l}400- \\
10000\end{array}$ & 0 & + & - & + \\
\hline $\begin{array}{c}\text { Graphene/ } \\
\text { CNTs }\end{array}$ & & $5-30$ & 0 & + & - & 0 \\
\hline $\begin{array}{l}\text { Conducting } \\
\text { Polymers }\end{array}$ & & $40-300$ & + & + & + & + \\
\hline \multirow[t]{3}{*}{ Composites } & $\begin{array}{c}\text { Metal - } \\
\text { Metal Oxide }\end{array}$ & $500-1000$ & - & - & 0 & 0 \\
\hline & $\begin{array}{l}\text { Metal - } \\
\text { Polymer }\end{array}$ & $200-1500$ & + & $0 /+$ & + & + \\
\hline & $\begin{array}{l}\text { CNT - } \\
\text { Polymer }\end{array}$ & $5-15$ & + & + & + & 0 \\
\hline
\end{tabular}




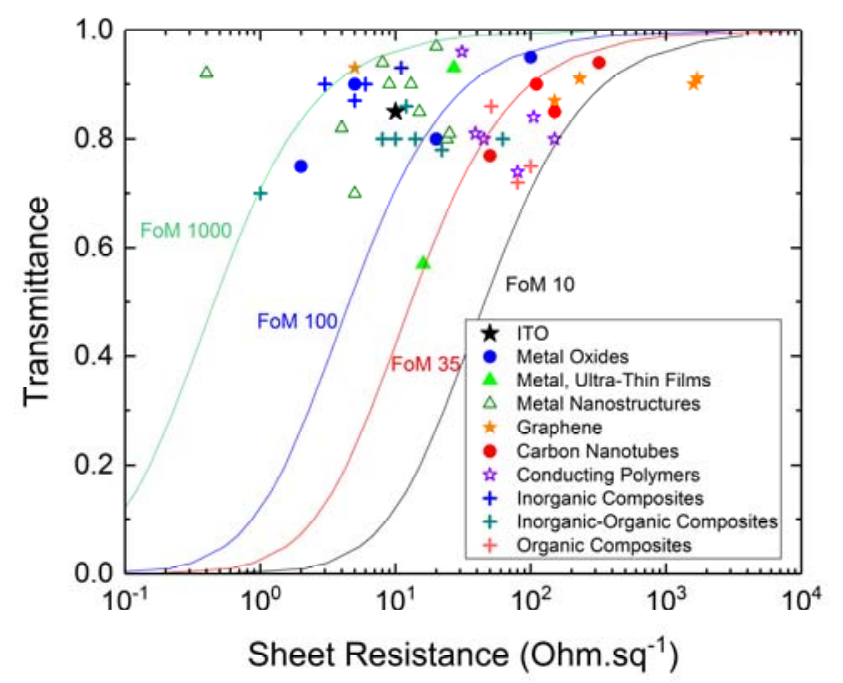

Figure 22 Transmittance $T$ (at 550nm) as a function of sheet resistance $R_{s}$ of transparent conducting films made from different materials.

\section{Acknowledgements}

The authors thank Arkema for the CIFRE PhD fellowship (\# 2013/0352) allocated to A.I.H. This work was performed within the framework of the Equipex ELORPrintTec ANR-10EQPX-28-01 and the LabEx AMADEUS ANR-10-LABEX-0042-AMADEUS with the help of the French state Initiative d'Excellence IdEx ANR-10-IDEX-003-02 and the LCPO/ Arkema INDUSTRIAL CHAIR “HOMERIC” ANR-13- CHIN-0002-01.

Received: ((will be filled in by the editorial staff))

Revised: ((will be filled in by the editorial staff)) Published online: ((will be filled in by the editorial staff)) 
[1] K. Ellmer, Nat. Photonics 2012, 6, 809.

[2] S. De, T. M. Higgins, P. E. Lyons, E. M. Doherty, P. N. Nirmalraj, W. J. Blau, J. J. Boland, J. N. Coleman, ACS Nano 2009, 3, 1767.

[3] R. G. Gordon, MRS Bull. 2000, 25, 52.

[4] D. Langley, G. Giusti, C. Mayousse, C. Celle, D. Bellet, J.-P. Simonato, Nanotechnology 2013, 24, 452001.

[5] I. Hamberg, C. G. Granqvist, J. Appl. Phys. 1986, 60, R123.

[6] C. G. Granqvist, Appl. Phys. A 1993, 57, 19.

[7] S. Ray, R. Banerjee, N. Basu, A. K. Batabyal, A. K. Barua, J. Appl. Phys. 1983, 54, 3497.

[8] J. S. Kim, M. Granström, R. H. Friend, N. Johansson, W. R. Salaneck, R. Daik, W. J. Feast, F. Cacialli, J. Appl. Phys. 1998, 84, 6859.

[9] K. Sugiyama, H. Ishii, Y. Ouchi, K. Seki, J. Appl. Phys. 1999, 87, 295.

[10] Y. Park, V. Choong, Y. Gao, B. R. Hsieh, C. W. Tang, Appl. Phys. Lett. 1996, 68, 2699.

[11] A. Solanki, Mater. Sci. Appl. 2011, 02, 1702.

[12] M. G. Mason, L. S. Hung, C. W. Tang, S. T. Lee, K. W. Wong, M. Wang, J. Appl. Phys. 1999, 86, 1688 .

[13] C. C. Wu, C. I. Wu, J. C. Sturm, A. Kahn, Appl. Phys. Lett. 1997, 70, 1348.

[14] K. L. Chopra, S. Major, D. K. Pandya, Thin Solid Films 1983, 102, 1.

[15] R. Bel Hadj Tahar, T. Ban, Y. Ohya, Y. Takahashi, J. Appl. Phys. 1998, 83, 2631.

[16] X. Yu, T. J. Marks, A. Facchetti, Nat. Mater. 2016, 15, 383.

[17] H. Kim, C. M. Gilmore, A. Piqué, J. S. Horwitz, H. Mattoussi, H. Murata, Z. H. Kafafi, D. B. Chrisey, J. Appl. Phys. 1999, 86, 6451.

[18] A. K. Kulkarni, K. H. Schulz, T. S. Lim, M. Khan, Thin Solid Films 1999, 345, 273. 
[19] W.-F. Wu, B.-S. Chiou, Thin Solid Films 1994, 247, 201.

[20] M. Kamei, Y. Shigesato, S. Takaki, Thin Solid Films 1995, 259, 38.

[21] H. Kim, J. S. Horwitz, G. P. Kushto, Z. H. Kafafi, D. B. Chrisey, Appl. Phys. Lett. 2001, $79,284$.

[22] C. G. Choi, K. No, W.-J. Lee, H.-G. Kim, S. O. Jung, W. J. Lee, W. S. Kim, S. J. Kim, C. Yoon, Thin Solid Films 1995, 258, 274.

[23] C. Guillén, J. Herrero, Thin Solid Films 2005, 480, 129.

[24] B. G. Lewis, D. C. Paine, MRS Bull. 2000, 25, 22.

[25] D. M. Mattox, Thin Solid Films 1991, 204, 25.

[26] R. Bel Hadj Tahar, T. Ban, Y. Ohya, Y. Takahashi, J. Appl. Phys. 1997, 82, 865.

[27] M. J. Alam, D. C. Cameron, Thin Solid Films 2002, 420, 76.

[28] J. Song, S. A. Kulinich, J. Li, Y. Liu, H. Zeng, Angew. Chem. 2015, 127, 472.

[29] M. Duta, M. Anastasescu, J. M. Calderon-Moreno, L. Predoana, S. Preda, M. Nicolescu, H. Stroescu, V. Bratan, I. Dascalu, E. Aperathitis, M. Modreanu, M. Zaharescu, M. Gartner, J. Mater. Sci. Mater. Electron. 2016, 27, 4913.

[30] J. Ederth, P. Heszler, A. Hultåker, G. A. Niklasson, C. G. Granqvist, Thin Solid Films 2003, 445, 199.

[31] S. Servaty, G. Michael, C. Heyer, S. Katusic, H. Miess, P. Kress, S. Servaty, G. Michael, C. Heyer, S. Katusic, H. Miess, P. Kress, Indium-Tin Oxides, 2002.

[32] S. Marikkannu, C. Sanjeeviraja, S. Piraman, A. Ayeshamariam, J. Mater. Sci. Mater. Electron. 2015, 26, 2531.

[33] N. Fellahi, M. Addou, A. Kachouane, M. E. Jouad, Z. Sofiani, Eur. Phys. J. Appl. Phys. 2016, 74, 24611.

[34] T. Maruyama, T. Tago, Appl. Phys. Lett. 1994, 64, 1395.

[35] J. E. Medvedeva, Phys. Rev. Lett. 2006, 97, DOI 10.1103/PhysRevLett.97.086401. 
[36] Z. Chen, L. Huang, Q. Zhang, Y. Xi, R. Li, W. Li, G. Xu, H. Cheng, J. Phys. Chem. C 2015, 119, 4789.

[37] K. L. Hoyer, A. H. Hubmann, A. Klein, Phys. Status Solidi A 2017, 214, 1600486.

[38] A. Kumar, C. Zhou, ACS Nano 2010, 4, 11.

[39] Y.-H. Tak, K.-B. Kim, H.-G. Park, K.-H. Lee, J.-R. Lee, Thin Solid Films 2002, 411, 12.

[40] A. R. Schlatmann, D. W. Floet, A. Hilberer, F. Garten, P. J. M. Smulders, T. M. Klapwijk, G. Hadziioannou, Appl. Phys. Lett. 1996, 69, 1764.

[41] S. A. Carter, M. Angelopoulos, S. Karg, P. J. Brock, J. C. Scott, Appl. Phys. Lett. 1997, 70, 2067.

[42] M. P. de Jong, D. P. L. Simons, M. A. Reijme, L. J. van IJzendoorn, A. W. Denier van der Gon, M. J. A. de Voigt, H. H. Brongersma, R. W. Gymer, Synth. Met. 2000, 110, 1.

[43] S. T. Lee, Z. Q. Gao, L. S. Hung, Appl. Phys. Lett. 1999, 75, 1404.

[44] D. E. Gallardo, C. Bertoni, S. Dunn, N. Gaponik, A. Eychmüller, Adv. Mater. 2007, 19, 3364.

[45] J. Cui, A. Wang, N. L. Edleman, J. Ni, P. Lee, N. R. Armstrong, T. J. Marks, Adv. Mater. 2001, 13, 1476.

[46] N. Zhou, D. B. Buchholz, G. Zhu, X. Yu, H. Lin, A. Facchetti, T. J. Marks, R. P. H. Chang, Adv. Mater. 2014, 26, 1098.

[47] S. Edinger, N. Bansal, M. Bauch, R. A. Wibowo, G. Újvári, R. Hamid, G. Trimmel, T. Dimopoulos, J. Mater. Sci. 2017, 52, 8591.

[48] T. Minami, Thin Solid Films 2008, 516, 5822.

[49] J. Bruneaux, H. Cachet, M. Froment, A. Messad, Thin Solid Films 1991, 197, 129.

[50] R. Pommier, C. Gril, J. Marucchi, Thin Solid Films 1981, 77, 91.

[51] E. Elangovan, K. Ramamurthi, Appl. Surf. Sci. 2005, 249, 183.

[52] A. E. Rakhshani, Y. Makdisi, H. A. Ramazaniyan, J. Appl. Phys. 1998, 83, 1049. 
[53] A. Andersson, N. Johansson, P. Broms, N. Yu, D. Lupo, W. R. Salaneck, others, Adv. Mater. 1998, 10, 859.

[54] T. Fukano, T. Motohiro, Sol. Energy Mater. Sol. Cells 2004, 82, 567.

[55] S. Major, S. Kumar, M. Bhatnagar, K. L. Chopra, Appl. Phys. Lett. 1986, 49, 394.

[56] A. V. Moholkar, S. M. Pawar, K. Y. Rajpure, C. H. Bhosale, J. H. Kim, Appl. Surf. Sci. 2009, 255, 9358.

[57] Q. Qiao, J. Beck, R. Lumpkin, J. Pretko, J. T. Mcleskey, Sol. Energy Mater. Sol. Cells 2006, 90, 1034.

[58] M. G. Helander, M. T. Greiner, Z. B. Wang, W. M. Tang, Z. H. Lu, J. Vac. Sci. Technol. Vac. Surf. Films 2011, 29, 011019.

[59] W.-H. Baek, M. Choi, T.-S. Yoon, H. H. Lee, Y.-S. Kim, Appl. Phys. Lett. 2010, 96, 133506.

[60] H. Liu, V. Avrutin, N. Izyumskaya, Ü. Özgür, H. Morkoç, Superlattices Microstruct. 2010, 48,458 .

[61] Y. Furubayashi, T. Hitosugi, Y. Yamamoto, K. Inaba, G. Kinoda, Y. Hirose, T. Shimada, T. Hasegawa, Appl. Phys. Lett. 2005, 86, 252101.

[62] D. Chen, G. Xu, L. Miao, S. Nakao, P. Jin, Surf. Coat. Technol. 2011, 206, 1020.

[63] U. Takeuchi, A. Chikamatsu, T. Hitosugi, H. Kumigashira, M. Oshima, Y. Hirose, T. Shimada, T. Hasegawa, J. Appl. Phys. 2010, 107, 023705.

[64] S. Mohri, Y. Hirose, S. Nakao, N. Yamada, T. Shimada, T. Hasegawa, J. Appl. Phys. 2012, 111, 093528.

[65] H. Liu, Y. F. Liu, P. P. Xiong, P. Chen, H. Y. Li, J. W. Hou, B. N. Kang, Y. Duan, IEEE Trans. Nanotechnol. 2017, PP, 1.

[66] H. Nanto, T. Minami, S. Shooji, S. Takata, J. Appl. Phys. 1984, 55, 1029.

[67] A. F. Aktaruzzaman, G. L. Sharma, L. K. Malhotra, Thin Solid Films 1991, 198, 67.

[68] W. Tang, D. C. Cameron, Thin Solid Films 1994, 238, 83. 
[69] J.-P. Lin, J.-M. Wu, Appl. Phys. Lett. 2008, 92, 134103.

[70] I. Lange, S. Reiter, J. Kniepert, F. Piersimoni, M. Pätzel, J. Hildebrandt, T. Brenner, S. Hecht, D. Neher, Appl. Phys. Lett. 2015, 106, 113302.

[71] T. L. Yang, D. H. Zhang, J. Ma, H. L. Ma, Y. Chen, Thin Solid Films 1998, 326, 60.

[72] J. Zhao, S. Xie, S. Han, Z. Yang, L. Ye, T. Yang, Synth. Met. 2000, 114, 251.

[73] J. H. Park, Y. C. Cho, J. M. Shin, S. Cha, C. R. Cho, H. S. Kim, S. J. Yoon, S. Jeong, S. E. Park, A. Lim, J.-KOREAN Phys. Soc. 2007, 51, 1968.

[74] T. Minami, Thin Solid Films 2008, 516, 1314.

[75] L. Hu, H. Wu, Y. Cui, MRS Bull. 2011, 36, 760.

[76] R. A. Hatton, M. R. Willis, M. A. Chesters, D. Briggs, J. Mater. Chem. 2003, 13, 722.

[77] R. B. Pode, C. J. Lee, D. G. Moon, J. I. Han, Appl. Phys. Lett. 2004, 84, 4614.

[78] S. Conoci, S. Petralia, P. Samorì, F. M. Raymo, S. Di Bella, S. Sortino, Adv. Funct. Mater. 2006, 16, 1425.

[79] D. S. Ghosh, L. Martinez, S. Giurgola, P. Vergani, V. Pruneri, Opt. Lett. 2009, 34, 325.

[80] B. O’Connor, C. Haughn, K.-H. An, K. P. Pipe, M. Shtein, Appl. Phys. Lett. 2008, 93, 223304.

[81] S. Schubert, L. Müller-Meskamp, K. Leo, Adv. Funct. Mater. 2014, 24, 6668.

[82] D. S. Ghosh, R. Betancur, T. L. Chen, V. Pruneri, J. Martorell, Sol. Energy Mater. Sol. Cells 2011, 95, 1228.

[83] P. B. Catrysse, S. Fan, Nano Lett. 2010, 10, 2944.

[84] C. P. Muzzillo, Sol. Energy Mater. Sol. Cells 2017, 169, 68.

[85] M.-G. Kang, L. J. Guo, Adv. Mater. 2007, 19, 1391.

[86] M.-G. Kang, M.-S. Kim, J. Kim, L. J. Guo, Adv. Mater. 2008, 20, 4408.

[87] J. Zou, H.-L. Yip, S. K. Hau, A. K.-Y. Jen, Appl. Phys. Lett. 2010, 96, 203301.

[88] B. Sciacca, J. van de Groep, A. Polman, E. C. Garnett, Adv. Mater. 2016, 28, 905.

[89] J. Kang, C.-G. Park, S.-H. Lee, C. Cho, D.-G. Choi, J.-Y. Lee, Nanoscale 2016, 8, 11217. 
[90] J. Schneider, P. Rohner, D. Thureja, M. Schmid, P. Galliker, D. Poulikakos, Adv. Funct. Mater. 2016, 26, 833.

[91] S. M. Yang, Y. S. Lee, Y. Jang, D. Byun, S.-H. Choa, Microelectron. Reliab. 2016, 65, 151.

[92] L. Müller-Meskamp, S. Schubert, T. Roch, S. Eckhardt, A.-F. Lasagni, K. Leo, Adv. Eng. Mater. 2015, 17, 1215.

[93] S. Eckhardt, M. Siebold, A. F. Lasagni, Opt. Express 2016, 24, A553.

[94] J. Jiu, T. Araki, J. Wang, M. Nogi, T. Sugahara, S. Nagao, H. Koga, K. Suganuma, E. Nakazawa, M. Hara, H. Uchida, K. Shinozaki, J. Mater. Chem. A 2014, 2, 6326.

[95] F. Cui, Y. Yu, L. Dou, J. Sun, Q. Yang, C. Schildknecht, K. Schierle-Arndt, P. Yang, Nano Lett. 2015, 15, 7610.

[96] M. Mohl, P. Pusztai, A. Kukovecz, Z. Konya, J. Kukkola, K. Kordas, R. Vajtai, P. M. Ajayan, Langmuir 2010, 26, 16496.

[97] W. Wang, G. Li, Z. Zhang, J. Cryst. Growth 2007, 299, 158.

[98] A. R. Rathmell, B. J. Wiley, Adv. Mater. 2011, 23, 4798.

[99] F. Meng, S. Jin, Nano Lett. 2012, 12, 234.

[100] D. Zhang, R. Wang, M. Wen, D. Weng, X. Cui, J. Sun, H. Li, Y. Lu, J. Am. Chem. Soc. 2012, 134, 14283.

[101] J.-Y. Lee, S. T. Connor, Y. Cui, P. Peumans, Nano Lett. 2008, 8, 689.

[102] J. Krantz, M. Richter, S. Spallek, E. Spiecker, C. J. Brabec, Adv. Funct. Mater. 2011, 21,4784 .

[103] P. Lee, J. Lee, H. Lee, J. Yeo, S. Hong, K. H. Nam, D. Lee, S. S. Lee, S. H. Ko, Adv. Mater. 2012, 24, 3326.

[104] L. Hu, H. S. Kim, J.-Y. Lee, P. Peumans, Y. Cui, ACS Nano 2010, 4, 2955.

[105] J. Liang, L. Li, K. Tong, Z. Ren, W. Hu, X. Niu, Y. Chen, Q. Pei, ACS Nano 2014, 8, 1590. 
[106] A. J. Stapleton, R. A. Afre, A. V. Ellis, J. G. Shapter, G. G. Andersson, J. S. Quinton, D. A. Lewis, Sci. Technol. Adv. Mater. 2013, 14, 035004.

[107] P.-C. Hsu, D. Kong, S. Wang, H. Wang, A. J. Welch, H. Wu, Y. Cui, J. Am. Chem. Soc. 2014, 136, 10593.

[108] P.-C. Hsu, S. Wang, H. Wu, V. K. Narasimhan, D. Kong, H. R. Lee, Y. Cui, Nat. Commun. 2013, 4, 2522.

[109] H. Wu, L. Hu, M. W. Rowell, D. Kong, J. J. Cha, J. R. McDonough, J. Zhu, Y. Yang, M. D. McGehee, Y. Cui, Nano Lett. 2010, 10, 4242.

[110] A. Iwan, A. Chuchmała, Prog. Polym. Sci. n.d., DOI 10.1016/j.progpolymsci.2012.08.001.

[111] M. Choe, B. H. Lee, G. Jo, J. Park, W. Park, S. Lee, W.-K. Hong, M.-J. Seong, Y. H. Kahng, K. Lee, T. Lee, Org. Electron. 2010, 11, 1864.

[112] H. Park, J. A. Rowehl, K. K. Kim, V. Bulovic, J. Kong, Nanotechnology 2010, 21, 505204.

[113] K. K. Kim, A. Reina, Y. Shi, H. Park, L.-J. Li, Y. H. Lee, J. Kong, Nanotechnology 2010, 21, 285205.

[114] Y. Sun, W. Zhang, H. Chi, Y. Liu, C. L. Hou, D. Fang, Renew. Sustain. Energy Rev. 2015, 43, 973.

[115] Y.-Z. Chen, H. Medina, H.-W. Tsai, Y.-C. Wang, Y.-T. Yen, A. Manikandan, Y.-L. Chueh, Chem. Mater. 2015, 27, 1646.

[116] X. Wang, L. Zhi, N. Tsao, Ž. Tomović, J. Li, K. Müllen, Angew. Chem. 2008, 120, 3032.

[117] J. Wu, M. Agrawal, H. A. Becerril, Z. Bao, Z. Liu, Y. Chen, P. Peumans, ACS Nano 2010, 4, 43

[118] E. Kymakis, E. Stratakis, M. M. Stylianakis, E. Koudoumas, C. Fotakis, Thin Solid Films 2011, 520, 1238. 
[119] P. Paletti, R. Pawar, G. Ulisse, F. Brunetti, G. Iannaccone, G. Fiori, 2D Mater. 2015, 2, 045006.

[120] Y. Wang, S. W. Tong, X. F. Xu, B. Özyilmaz, K. P. Loh, Adv. Mater. 2011, 23, 1514.

[121] P.-C. Ma, N. A. Siddiqui, G. Marom, J.-K. Kim, Compos. Part Appl. Sci. Manuf. 2010, $41,1345$.

[122] M. F. L. D. Volder, S. H. Tawfick, R. H. Baughman, A. J. Hart, Science 2013, 339, 535.

[123] M. Kaempgen, G. S. Duesberg, S. Roth, Appl. Surf. Sci. 2005, 252, 425.

[124] M. C. Hersam, Nat. Nanotechnol. 2008, 3, 387.

[125] R. Krupke, F. Hennrich, H. v Löhneysen, M. M. Kappes, Science 2003, 301, 344.

[126] M. Zheng, A. Jagota, E. D. Semke, B. A. Diner, R. S. Mclean, S. R. Lustig, R. E. Richardson, N. G. Tassi, Nat. Mater. 2003, 2, 338.

[127] R. Voggu, K. V. Rao, S. J. George, C. N. R. Rao, J. Am. Chem. Soc. 2010, 132, 5560.

[128] M. S. Arnold, A. A. Green, J. F. Hulvat, S. I. Stupp, M. C. Hersam, Nat. Nanotechnol. 2006, 1,60 .

[129] R. C. Tenent, T. M. Barnes, J. D. Bergeson, A. J. Ferguson, B. To, L. M. Gedvilas, M. J. Heben, J. L. Blackburn, Adv. Mater. 2009, 21, 3210.

[130] M. Giulianini, E. R. Waclawik, J. M. Bell, M. De Crescenzi, P. Castrucci, M. Scarselli, N. Motta, Appl. Phys. Lett. 2009, 95, 013304.

[131] K. Okazaki, Phys. Rev. B 2003, 68, DOI 10.1103/PhysRevB.68.035434.

[132] J. van de Lagemaat, T. M. Barnes, G. Rumbles, S. E. Shaheen, T. J. Coutts, C. Weeks, I. Levitsky, J. Peltola, P. Glatkowski, Appl. Phys. Lett. 2006, 88, 233503.

[133] N. Imazu, T. Fujigaya, N. Nakashima, Sci. Technol. Adv. Mater. 2014, 15, 025005.

[134] A. Kaskela, A. G. Nasibulin, M. Y. Timmermans, B. Aitchison, A. Papadimitratos, Y. Tian, Z. Zhu, H. Jiang, D. P. Brown, A. Zakhidov, E. I. Kauppinen, Nano Lett. 2010, 10, 4349.

[135] I. Jeon, K. Cui, T. Chiba, A. Anisimov, A. G. Nasibulin, E. I. Kauppinen, S. Maruyama, Y. Matsuo, J. Am. Chem. Soc. 2015, 137, 7982. 
[136] Z. Li, S. A. Kulkarni, P. P. Boix, E. Shi, A. Cao, K. Fu, S. K. Batabyal, J. Zhang, Q.

Xiong, L. H. Wong, N. Mathews, S. G. Mhaisalkar, ACS Nano 2014, 8, 6797.

[137] V. C. Tung, L.-M. Chen, M. J. Allen, J. K. Wassei, K. Nelson, R. B. Kaner, Y. Yang, Nano Lett. 2009, 9, 1949.

[138] S. H. Kim, W. Song, M. W. Jung, M.-A. Kang, K. Kim, S.-J. Chang, S. S. Lee, J. Lim, J. Hwang, S. Myung, K.-S. An, Adv. Mater. 2014, 26, 4247.

[139] I. N. Kholmanov, C. W. Magnuson, R. Piner, J.-Y. Kim, A. E. Aliev, C. Tan, T. Y. Kim, A. A. Zakhidov, G. Sberveglieri, R. H. Baughman, R. S. Ruoff, Adv. Mater. 2015, 27, 3053.

[140] K.-H. Tu, S.-S. Li, W.-C. Li, D.-Y. Wang, J.-R. Yang, C.-W. Chen, Energy Environ. Sci. 2011, 4, 3521.

[141] P.-C. Wang, L.-H. Liu, D. Alemu Mengistie, K.-H. Li, B.-J. Wen, T.-S. Liu, C.-W. Chu, Displays 2013, 34, 301.

[142] W. W. Focke, G. E. Wnek, Y. Wei, J. Phys. Chem. 1987, 91, 5813.

[143] D. L. Cowan, V. Priest, T. R. Marrero, D. W. Slaughter, J. Phys. Chem. Solids 1990, 51, 307.

[144] J. Stejskal, I. Sapurina, J. Prokeš, J. Zemek, Synth. Met. 1999, 105, 195.

[145] Y. Cao, G. M. Treacy, P. Smith, A. J. Heeger, Appl. Phys. Lett. 1992, 60, 2711.

[146] G. Gustafsson, G. M. Treacy, Y. Cao, F. Klavetter, N. Colaneri, A. J. Heeger, Synth. Met. 1993, 57, 4123.

[147] Y. Yang, A. J. Heeger, Appl. Phys. Lett. 1994, 64, 1245.

[148] O. Bubnova, Z. U. Khan, A. Malti, S. Braun, M. Fahlman, M. Berggren, X. Crispin, Nat. Mater. 2011, 10, 429.

[149] J. P. Lock, S. G. Im, K. K. Gleason, Macromolecules 2006, 39, 5326.

[150] T. A. Skotheim, Handbook of Conducting Polymers, Second Edition, CRC Press, 1997.

[151] A. Elschner, S. Kirchmeyer, W. Lovenich, U. Merker, K. Reuter, PEDOT: Principles and Applications of an Intrinsically Conductive Polymer, CRC Press, 2010. 
[152] G. Zotti, S. Zecchin, G. Schiavon, F. Louwet, L. Groenendaal, X. Crispin, W. Osikowicz, W. Salaneck, M. Fahlman, Macromolecules 2003, 36, 3337.

[153] A. I. Hofmann, D. Katsigiannopoulos, M. Mumtaz, I. Petsagkourakis, G. Pecastaings, G. Fleury, C. Schatz, E. Pavlopoulou, C. Brochon, G. Hadziioannou, E. Cloutet, Macromolecules 2017, 50, 1959.

[154] L. Lindell, A. Burquel, F. L. E. Jakobsson, V. Lemaur, M. Berggren, R. Lazzaroni, J. Cornil, W. R. Salaneck, X. Crispin, Chem. Mater. 2006, 18, 4246.

[155] F. L. E. Jakobsson, X. Crispin, L. Lindell, A. Kanciurzewska, M. Fahlman, W. R. Salaneck, M. Berggren, Chem. Phys. Lett. 2006, 433, 110.

[156] A. M. Nardes, M. Kemerink, M. M. de Kok, E. Vinken, K. Maturova, R. A. J. Janssen, Org. Electron. 2008, 9, 727.

[157] L. Groenendaal, G. Zotti, P.-H. Aubert, S. m. Waybright, J. r. Reynolds, Adv. Mater. 2003, 15,855 .

[158] J. Xia, N. Masaki, K. Jiang, S. Yanagida, J. Mater. Chem. 2007, 17, 2845.

[159] E. Poverenov, M. Li, A. Bitler, M. Bendikov, Chem. Mater. 2010, 22, 4019.

[160] J. Yan, C. Sun, F. Tan, X. Hu, P. Chen, S. Qu, S. Zhou, J. Xu, Sol. Energy Mater. Sol. Cells 2010, 94, 390.

[161] S. Ahmad, J.-H. Yum, Z. Xianxi, M. Grätzel, H.-J. Butt, M. K. Nazeeruddin, J. Mater. Chem. 2010, 20, 1654.

[162] C. Louet, S. Cantin, J.-P. Dudon, P.-H. Aubert, F. Vidal, C. Chevrot, Sol. Energy Mater. Sol. Cells 2015, 143, 141.

[163] R. Corradi, S. P. Armes, Synth. Met. 1997, 84, 453.

[164] F. Louwet, L. Groenendaal, J. Dhaen, J. Manca, J. Van Luppen, E. Verdonck, L. Leenders, Synth. Met. 2003, 135-136, 115.

[165] N. Paradee, A. Sirivat, Polym. Int. 2013, n/a.

[166] J. Wang, G. Cai, X. Zhu, X. Zhou, J. Appl. Polym. Sci. 2012, 124, 109. 
[167] L. Groenendaal, F. Jonas, D. Freitag, H. Pielartzik, J. R. Reynolds, Adv. Mater. 2000, $12,481$.

[168] C.-H. Wu, T.-M. Don, W.-Y. Chiu, Polymer 2011, 52, 1375.

[169] C. Jiang, G. Chen, X. Wang, Synth. Met. 2012, 162, 1968.

[170] M. R. Nabid, S. Asadi, M. Shamsianpour, R. Sedghi, S. Osati, N. Safari, React. Funct. Polym. 2010, 70, 75.

[171] Y.-H. Ha, N. Nikolov, S. K. Pollack, J. Mastrangelo, B. D. Martin, R. Shashidhar, Adv. Funct. Mater. 2004, 14, 615.

[172] D. Hohnholz, A. G. MacDiarmid, D. M. Sarno, J. Wayne E. Jones, Chem. Commun. 2001, 2444

[173] D. M. de Leeuw, P. A. Kraakman, P. F. G. Bongaerts, C. M. J. Mutsaers, D. B. M. Klaassen, Synth. Met. 1994, 66, 263.

[174] J. H. Chen, C.-A. Dai, W.-Y. Chiu, J. Polym. Sci. Part Polym. Chem. 2008, 46, 1662.

[175] O. Bubnova, Z. U. Khan, H. Wang, S. Braun, D. R. Evans, M. Fabretto, P. Hojati-Talemi, D. Dagnelund, J.-B. Arlin, Y. H. Geerts, S. Desbief, D. W. Breiby, J. W. Andreasen, R. Lazzaroni, W. M. Chen, I. Zozoulenko, M. Fahlman, P. J. Murphy, M. Berggren, X. Crispin, Nat. Mater. 2013, 13, 190.

[176] J. S. Choi, J.-H. Yim, D.-W. Kim, J.-K. Jeon, Y. S. Ko, Y. Kim, Synth. Met. 2009, 159, 2506.

[177] B. Winther-Jensen, K. West, Macromolecules 2004, 37, 4538.

[178] M. V. Fabretto, D. R. Evans, M. Mueller, K. Zuber, P. Hojati-Talemi, R. D. Short, G. G. Wallace, P. J. Murphy, Chem. Mater. 2012, 24, 3998.

[179] S. Admassie, O. Inganäs, W. Mammo, E. Perzon, M. R. Andersson, Synth. Met. 2006, $156,614$.

[180] B. Winther-Jensen, F. C. Krebs, Sol. Energy Mater. Sol. Cells 2006, 90, 123. 
[181] A. M. Nardes, M. Kemerink, R. A. J. Janssen, J. A. M. Bastiaansen, N. M. M. Kiggen, B. M. W. Langeveld, A. J. J. M. van Breemen, M. M. de Kok, Adv. Mater. 2007, 19, 1196.

[182] S. K. . Jönsson, J. Birgerson, X. Crispin, G. Greczynski, W. Osikowicz, A. . Denier van der Gon, W. . Salaneck, M. Fahlman, Synth. Met. 2003, 139, 1.

[183] H. Shi, C. Liu, Q. Jiang, J. Xu, Adv. Electron. Mater. 2015, 1, 1500017.

[184] J. Ouyang, C.-W. Chu, F.-C. Chen, Q. Xu, Y. Yang, Adv. Funct. Mater. 2005, 15, 203.

[185] J. Y. Kim, J. H. Jung, D. E. Lee, J. Joo, Synth. Met. 2002, 126, 311.

[186] J. Ouyang, Q. Xu, C.-W. Chu, Y. Yang, G. Li, J. Shinar, Polymer 2004, 45, 8443.

[187] Y. Xia, J. Ouyang, J. Mater. Chem. 2011, 21, 4927.

[188] X. Crispin, F. L. E. Jakobsson, A. Crispin, P. C. M. Grim, P. Andersson, A. Volodin, C. van Haesendonck, M. Van der Auweraer, W. R. Salaneck, M. Berggren, Chem. Mater. 2006, $18,4354$.

[189] X. Crispin, S. Marciniak, W. Osikowicz, G. Zotti, A. W. D. van der Gon, F. Louwet, M. Fahlman, L. Groenendaal, F. De Schryver, W. R. Salaneck, J. Polym. Sci. Part B Polym. Phys. 2003, 41, 2561.

[190] A. M. Nardes, R. A. J. Janssen, M. Kemerink, Adv. Funct. Mater. 2008, 18, 865.

[191] I. Cruz-Cruz, M. Reyes-Reyes, M. A. Aguilar-Frutis, A. G. Rodriguez, R. LópezSandoval, Synth. Met. 2010, 160, 1501.

[192] Y. H. Kim, C. Sachse, M. L. Machala, C. May, L. Müller-Meskamp, K. Leo, Adv. Funct. Mater. 2011, 21, 1076.

[193] S.-I. Na, S.-S. Kim, J. Jo, D.-Y. Kim, Adv. Mater. 2008, 20, 4061.

[194] H. Do, M. Reinhard, H. Vogeler, A. Puetz, M. F. G. Klein, W. Schabel, A. Colsmann, U. Lemmer, Thin Solid Films 2009, 517, 5900.

[195] E. Ahlswede, W. Mühleisen, M. W. bin Moh Wahi, J. Hanisch, M. Powalla, Appl. Phys. Lett. 2008, 92, 143307. 
[196] S. Timpanaro, M. Kemerink, F. J. Touwslager, M. M. De Kok, S. Schrader, Chem. Phys. Lett. 2004, 394, 339.

[197] L. Ouyang, C. Musumeci, M. J. Jafari, T. Ederth, O. Inganäs, ACS Appl. Mater. Interfaces 2015, 7, 19764.

[198] N. Kim, B. H. Lee, D. Choi, G. Kim, H. Kim, J.-R. Kim, J. Lee, Y. H. Kahng, K. Lee, Phys. Rev. Lett. 2012, 109, 106405.

[199] L. A. A. Pettersson, S. Ghosh, O. Inganäs, Org. Electron. 2002, 3, 143.

[200] J. Zhou, D. H. Anjum, G. Lubineau, E. Q. Li, S. T. Thoroddsen, Macromolecules 2015, 48, 5688 .

[201] Q. Wei, M. Mukaida, Y. Naitoh, T. Ishida, Adv. Mater. 2013, 25, 2831.

[202] J. Ouyang, Displays 2013, 34, 423.

[203] Y. Xia, J. Ouyang, Macromolecules 2009, 42, 4141.

[204] Y. Xia, J. Ouyang, Org. Electron. 2010, 11, 1129.

[205] R. J. Murphy, K. M. Weigandt, D. Uhrig, A. Alsayed, C. Badre, L. Hough, M. Muthukumar, Macromolecules 2015, 48, 8989.

[206] M. Reyes-Reyes, I. Cruz-Cruz, R. López-Sandoval, J. Phys. Chem. C 2010, 114, 20220.

[207] Z. Yu, Y. Xia, D. Du, J. Ouyang, ACS Appl. Mater. Interfaces 2016, 8, 11629.

[208] C. Badre, L. Marquant, A. M. Alsayed, L. A. Hough, Adv. Funct. Mater. 2012, 22, 2723.

[209] R. M. Howden, E. D. McVay, K. K. Gleason, J Mater Chem A 2013, 1, 1334.

[210] Y. Xia, J. Ouyang, ACS Appl. Mater. Interfaces 2010, 2, 474.

[211] S. Mukherjee, R. Singh, S. Gopinathan, S. Murugan, S. Gawali, B. Saha, J. Biswas, S. Lodha, A. Kumar, ACS Appl. Mater. Interfaces 2014, 6, 17792.

[212] A. I. Hofmann, W. T. T. Smaal, M. Mumtaz, D. Katsigiannopoulos, C. Brochon, F. Schütze, O. R. Hild, E. Cloutet, G. Hadziioannou, Angew. Chem. Int. Ed. 2015, 8506.

[213] M. Jørgensen, K. Norrman, F. C. Krebs, Sol. Energy Mater. Sol. Cells 2008, 92, 686.

[214] W. Greenbank, L. Hirsch, G. Wantz, S. Chambon, Appl. Phys. Lett. 2015, 107, 263301. 
[215] R. Rösch, D. M. Tanenbaum, M. Jørgensen, M. Seeland, M. Bärenklau, M. Hermenau, E. Voroshazi, M. T. Lloyd, Y. Galagan, B. Zimmermann, U. Würfel, M. Hösel, H. F. Dam, S. A. Gevorgyan, S. Kudret, W. Maes, L. Lutsen, D. Vanderzande, R. Andriessen, G. TeranEscobar, M. Lira-Cantu, A. Rivaton, G. Y. Uzunoğlu, D. Germack, B. Andreasen, M. V. Madsen, K. Norrman, H. Hoppe, F. C. Krebs, Energy Environ. Sci. 2012, 5, 6521.

[216] C. Guillén, J. Herrero, Sol. Energy Mater. Sol. Cells 2008, 92, 938.

[217] J.-A. Jeong, H.-K. Kim, Sol. Energy Mater. Sol. Cells 2009, 93, 1801.

[218] D. R. Sahu, S.-Y. Lin, J.-L. Huang, Appl. Surf. Sci. 2006, 252, 7509.

[219] C.-H. Lee, R. Pandey, B.-Y. Wang, W.-K. Choi, D.-K. Choi, Y.-J. Oh, Sol. Energy Mater. Sol. Cells 2015, 132, 80.

[220] A. Kim, Y. Won, K. Woo, S. Jeong, J. Moon, Adv. Funct. Mater. 2014, 24, 2462.

[221] F. S. F. Morgenstern, D. Kabra, S. Massip, T. J. K. Brenner, P. E. Lyons, J. N. Coleman, R. H. Friend, Appl. Phys. Lett. 2011, 99, 183307.

[222] K. Zilberberg, F. Gasse, R. Pagui, A. Polywka, A. Behrendt, S. Trost, R. Heiderhoff, P. Görrn, T. Riedl, Adv. Funct. Mater. 2014, 24, 1671.

[223] C.-C. Chen, L. Dou, R. Zhu, C.-H. Chung, T.-B. Song, Y. B. Zheng, S. Hawks, G. Li, P. S. Weiss, Y. Yang, ACS Nano 2012, 6, 7185.

[224] K.-H. Ok, J. Kim, S.-R. Park, Y. Kim, C.-J. Lee, S.-J. Hong, M.-G. Kwak, N. Kim, C. J. Han, J.-W. Kim, Sci. Rep. 2015, 5, 9464.

[225] Z. Yu, L. Li, Q. Zhang, W. Hu, Q. Pei, Adv. Mater. 2011, 23, 4453.

[226] X.-Y. Zeng, Q.-K. Zhang, R.-M. Yu, C.-Z. Lu, Adv. Mater. 2010, 22, 4484.

[227] W. Gaynor, G. F. Burkhard, M. D. McGehee, P. Peumans, Adv. Mater. 2011, 23, 2905.

[228] J. Song, J. Li, J. Xu, H. Zeng, Nano Lett. 2014, 14, 6298.

[229] B. Deng, P.-C. Hsu, G. Chen, B. N. Chandrashekar, L. Liao, Z. Ayitimuda, J. Wu, Y. Guo, L. Lin, Y. Zhou, M. Aisijiang, Q. Xie, Y. Cui, Z. Liu, H. Peng, Nano Lett. 2015, 15, 4206. [230] D.-H. Kim, K.-C. Yu, Y. Kim, J.-W. Kim, ACS Appl. Mater. Interfaces 2015, 7, 15214. 
[231] J. Lee, P. Lee, H. B. Lee, S. Hong, I. Lee, J. Yeo, S. S. Lee, T.-S. Kim, D. Lee, S. H. Ko, Adv. Funct. Mater. 2013, 23, 4171.

[232] J.-H. Lee, H.-S. Shin, Y.-J. Noh, S.-I. Na, H.-K. Kim, Sol. Energy Mater. Sol. Cells 2013, 114, 15.

[233] C. Mayousse, C. Celle, A. Carella, J.-P. Simonato, Nano Res. 2014, 7, 315.

[234] M.-G. Kang, H. Joon Park, S. Hyun Ahn, L. Jay Guo, Sol. Energy Mater. Sol. Cells 2010, 94, 1179.

[235] A. Khan, S. Lee, T. Jang, Z. Xiong, C. Zhang, J. Tang, L. J. Guo, W.-D. Li, Small 2016, 12,3021 .

[236] S. De, P. E. Lyons, S. Sorel, E. M. Doherty, P. J. King, W. J. Blau, P. N. Nirmalraj, J. J. Boland, V. Scardaci, J. Joimel, J. N. Coleman, ACS Nano 2009, 3, 714.

[237] L. Valentini, M. Cardinali, D. Bagnis, J. M. Kenny, Carbon 2008, 46, 1513.

[238] G.-F. Wang, X.-M. Tao, R.-X. Wang, Nanotechnology 2008, 19, 145201.

[239] H. T. Ham, Y. S. Choi, M. G. Chee, M. H. Cha, I. J. Chung, Polym. Eng. Sci. 2008, 48, 1.

[240] S.-H. Jo, Y.-K. Lee, J.-W. Yang, W.-G. Jung, J.-Y. Kim, Synth. Met. 2012, 162, 1279.

[241] E.-C. Cho, C.-P. Li, J.-H. Huang, K.-C. Lee, J.-H. Huang, ACS Appl. Mater. Interfaces 2015, 7, 11668 .

[242] N. Ferrer-Anglada, V. Gomis, Z. El-Hachemi, U. D. Weglikovska, M. Kaempgen, S. Roth, Phys. Status Solidi A 2006, 203, 1082.

[243] S. L. Hellstrom, H. W. Lee, Z. Bao, ACS Nano 2009, 3, 1423. 


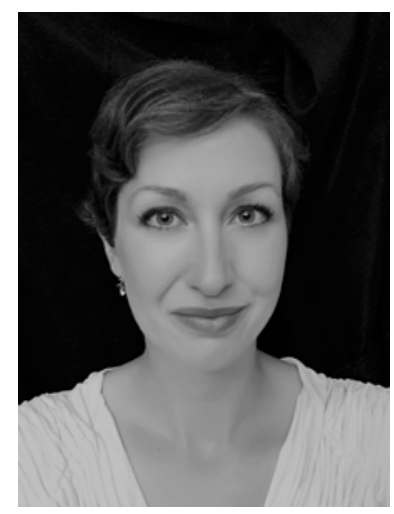

Dr. Anna I. Hofmann received a double Master degree in Material Science from the University of Bordeaux, France, and from the University of Augsburg, Germany, in 2013. In 2016 she completed her doctoral studies on aqueous dispersions of conducting PEDOT:polyelectrolyte complexes under the supervision of Professor Georges Hadziioannou and Dr. Eric Cloutet at the University of Bordeaux. Currently she is working as postdoctoral researcher in the group of Professor Christian Müller at the Chalmers University of Technology, Sweden, focusing on organic thermoelectrics.

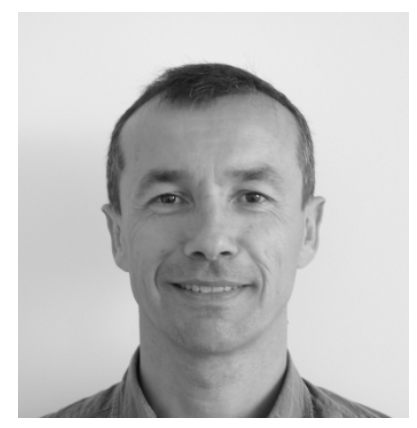

Dr. Eric CLOUTET received a $\mathrm{PhD}$ in polymer chemistry from the University of Bordeaux (1996) and did a postdoc at the University of Akron (Ohio, USA) in 1997. Then, he joined the CNRS at the University of Paris 13 and moved to the Laboratoire de Chimie des Polymères Organiques (LCPO, Univ. Bordeaux) in 2001. He is currently a CNRS senior researcher at LCPO working on the design and formulation of advanced functional polymers for applications in energy, lithography, optoelectronics, displays, etc. His research interests include the 
development of various (co)polymers via various polymerization routes both in homogeneous and heterogeneous media.

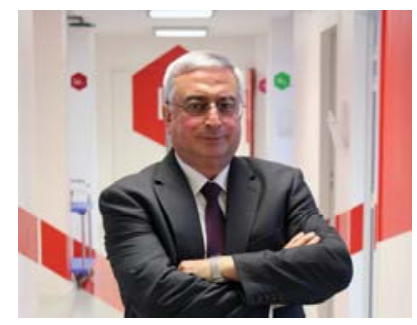

Georges Hadziioannou is Chemistry Professor at the University of Bordeaux since 2/2009, Holder of the Industrial Chair of ARKEMA/ANR HOMERIC "Hierarchical assembled Organic Materials for ElctRonICs", Member of the ARKEMA Corporate Scientific Board and Senior Member of the IUF, Chair of "Physical chemistry of Polymers". He was elected in 2017 foreign member of the US National Academy of Engineering. His career is characterized by a strong commitment to fundamental research at different universities and research institutes worldwide and an important industrial tenure at IBM Almaden Research Laboratory (San Jose, California). He has pioneered work on nanostructured polymers materials with innovations in flexible and printable organic electronic materials as well as energy and information technologies. He is the author of 447 publications $(\mathrm{H}=62), 167$ invited talks and 45 patents, $50 \mathrm{PhD}$ 's, he wrote a Textbook on "Polymer Electronics", and he was co-founder of 2 startups.

Education: 1975-1980: Univ. Louis Pasteur and Centre de Recherches sur les Macromolécules, Strasbourg - Thèses d'Etat ès Sciences Physiques and These of $3 \mathrm{e}$ cycle, DEA in Macromolecular Physical Chemistry; 1971-1975: Aristotle University of Thessaloniki (Greece), Master in Chemistry 
A. I. Hofmann, E. Cloutet*, G. Hadziioannou*

Materials for Transparent Electrodes: From Metal Oxides to Organic Alternatives

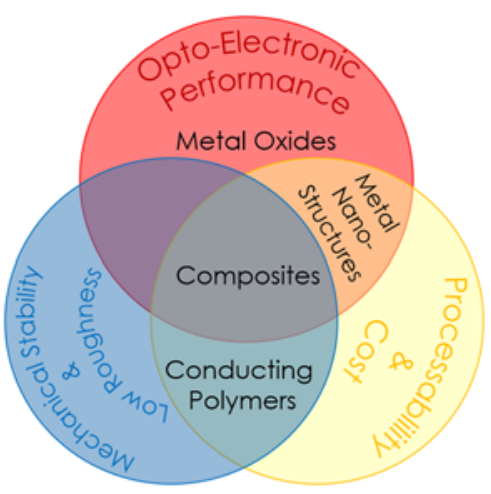

Different classes of transparent conductors and their potential for the application as

transparent electrodes are presented, comprising brief descriptions of the fundamental principles as well as the latest achievements in the field. Various inorganic and organic materials are compared, not only regarding their opto-electronic performance, but also regarding their processability, flexibility and potential for the integration in devices. 